\title{
A LIQUID WALL BOILER AND MODERATOR (BAM) FOR HEAVY ION-PELLET FUSION REACTORS
}

JAMES R. POWELL, OTTO LAZARETH, AND JOHN FILLO

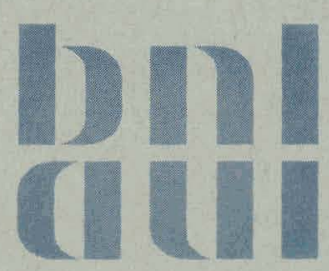

November 1977

BROOKHAVEN NATIONAL LABORATORY

ASSOCIATED UNIVERSITIES, INC.

UNDER CONTRACT NO. EY-76-C-02-0016 WITH THE

UNITED STATES DEPARTMENT OF ENERGY 


\section{DISCLAIMER}

This report was prepared as an account of work sponsored by an agency of the United States Government. Neither the United States Government nor any agency Thereof, nor any of their employees, makes any warranty, express or implied, or assumes any legal liability or responsibility for the accuracy, completeness, or usefulness of any information, apparatus, product, or process disclosed, or represents that its use would not infringe privately owned rights. Reference herein to any specific commercial product, process, or service by trade name, trademark, manufacturer, or otherwise does not necessarily constitute or imply its endorsement, recommendation, or favoring by the United States Government or any agency thereof. The views and opinions of authors expressed herein do not necessarily state or reflect those of the United States Government or any agency thereof. 


\section{DISCLAIMER}

Portions of this document may be illegible in electronic image products. Images are produced from the best available original document. 
BNL-50744

UC-20

(Magnetic Fusion Energy - TID-4500)

\section{A LLQUID WALL BOILER AND MODERATOR (BAM) FOR HEAVY ION-PELLET FUSION REACTORS}

JAMES R. POWELL, OTTO LAZARETH, AND JOHN FILLO

November 1977

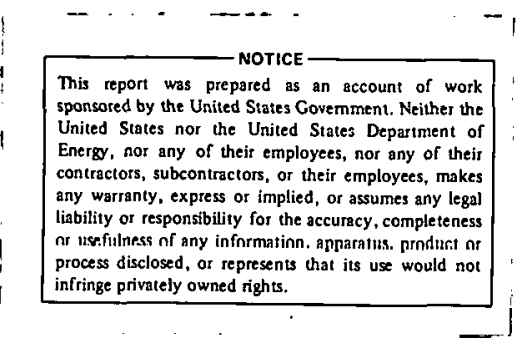

BROOKHAVEN NATIONAL LABORATORY

UPTON, NEW YORK 11973 


\section{NOTIGE}

This report was prepared as an account of work sponsored by the United States Government. Neither the United States nnr the I Inited Stateo Dopartment of Euclgy (DOE), nor any of their employees, nor any of their contractors, subcontractors, or

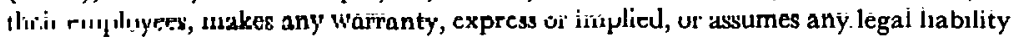
or responsibility for the accuracy, completeness or usefulness of any information, apparatus, product or process disclosed, or represents that its use would not infringe privately owned rights.

Printed in the United States of America Available from

National Technical Information Service

U.S. Department of Commerce

5285 Port Royal Road

Springfield, VA 22161

Price: Printed Copy $\$ 4.50$; Microfiche $\$ 3.00$

December 1977 


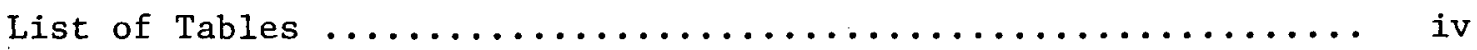

L. st of Figures $\ldots \ldots \ldots \ldots \ldots \ldots \ldots \ldots \ldots \ldots \ldots \ldots \ldots \ldots \ldots \ldots \ldots, v$

Introduction $\ldots \ldots \ldots \ldots \ldots \ldots \ldots \ldots \ldots \ldots \ldots \ldots \ldots \ldots \ldots \ldots \ldots \ldots$

General Features of the BAM Concept $\ldots \ldots \ldots \ldots \ldots \ldots \ldots \ldots \ldots \ldots$

Effects of Pellet Explosion on Liquid Wall .............. 10

Condensation of Vapor Produced by Pellet Explosions .......... 15

Tr1t1um Breeding and Energy Absorption in the Liquid Wall

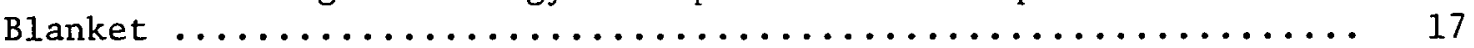

Pumping Power Requirements for Liquid Walls .............. 19

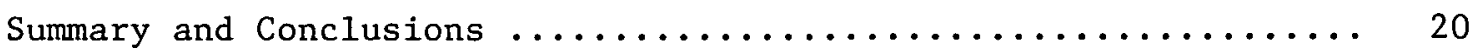

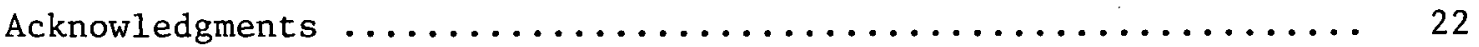

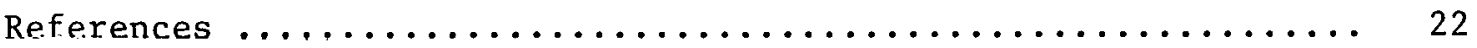

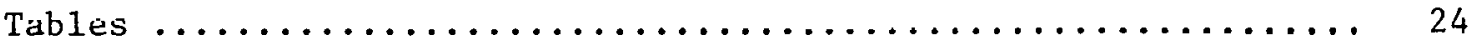

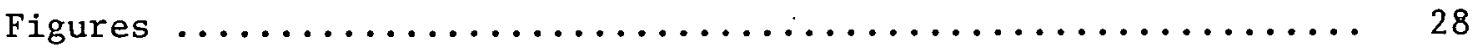




\section{List of Tables}

Title

Page

Table 1

End Closure Options

Table 2

Liquid Wall Velocity Components

Table 3

Velocity Component Expressions

Table 4

Parameters Affecting $\mathrm{V}_{1}, \mathrm{~V}_{2}$, and $\mathrm{V}_{3}$

Table 5

Typical BAM Reactor Parameters

Table 6

Physical Properties of Candldate Liquid Wall Materials 
Figure 1

Figure 2

Figure 3

Figure 4

Figure 5

Figure 6

Figure 7

Figure 8

Figure 9

Figure 10

Figure 11

Figure 12

Figure 13

Figure 14

Figure 15
Liquid Wall Boiler for Fusion Pellet Systems

28

Detail View of Liquid Wall

28

Flowsheet of BAM Reactor

29

Idealized Expansion Behavior of Liquid Wall After Pellet Explosion

30

Vapor Pressure of Candidate Liquid Walls as a Function of Temperature

Outwards Expansion Velocity of LIquid Wall vs.

Pellet Yield, for Different Candidate Liquid Walls

Kinetic Energy of Expansion of Liquid Wall vs.

Pellet Yield, for Different Candidate Liquid Walls

Expansion Velocity of LIquid Lead Wall vs. Pellet Yle1d, for Different Pellet Masses

Expansion Velocity of Liquid Lead Wall vs. Pellet Yield, for Different Degrees of Neutron Moderation in Pellet

Expansion Velocity of Liquid Lead Wall vs. Pellet Yield, for Different Vapor Condensation Times

Expansion Velocity of Liquid Lead Wall vs. Pellet Yicld, for Different Reaction Chamber Sizess

Temperature Profile vs. Time in Liquid Drops with Condensing Vapor

Vapor Condensation Time and Thickness of Liquid

Drop Zone vs. Pellet Yield

Tritium Breeding Ratio in Liquid Wall vs. Thickness of Liquid Wa11, for Candidate Liquid Wall

Materials

Tritium Breeding Ratio in Liquid Lead Wall vs. Thickness of Lead Wall, for Different $\mathrm{Pb} / \mathrm{Li} 6$

Ratios 


\section{List of Figures (Cont'd)}

Figure 16

Tritfum Breeding Ratio in Liquid Lead Wall vs.

Thickness of Lead Wall, for Different $\mathrm{Pb} / \mathrm{Li}^{6}$

Ratios and Thinner Graphite Zones

Figure 17

Direct Fusion Energy Absorption in Liquid Wall and Coolant vs. Thickness of Liquid Wall, for Candidate Liquid Wall Materials

Figure 18

Pumping Power Requirements for Liquid Wall vs.

Pellet Yield, for Candidace Liquid Wall Materials 


\section{Introduction}

Heavy ion-pellet fusion reactors have become of great interest in the last few months. (1) As with other inertial confinement concepts, e.g., laserpellet or electron-beam pellet reactors, the plasma stability problems associated with magnetic confinement approaches can be avoided.. It appears feasible in principle to generate and focus pulsed heavy-ion beams of sufficient energy content and power to ignite DT fusion pellets. (1) The necessary accelerator systems appear to be closer to current technology than the corresponding laser systems for laser-pellet reactors. Also, the efficiency of ion-beam production (electric energy to beam energy) 'should be considerably higher than for laser beam production.

Pellet fusion will typically release a large amount of energy, i.e., several gigajoules, ${ }^{(1)}$ in a very short time, i.e., several nanoseconds. Most of the fusion energy release will be in the form of neutrons which will generate deeply into the surrounding blanket, but a substantial fraction of the fusion energy will appear as X-rays and kinetic energy of the pellet debris. This portion will essentially be absorbed on the surface of the blanket facing the exploding pellet. Regardless of the energy release mode, the rapid local hea.ting poses very severe shock and fatigue problems for solid blanket structures. These effects, combined with the intense radiation damage that will be produced by the high energy fusion neutrons, make solid structures quite unattractive.

Wetted wall blankets have been proposed ${ }^{(2)}$ for pellet fusion reactors. The surface of these blankets is a relatively thin film of liquid (e.g., lithium) that partially evaporates when the X-rays and pellet debris hit. Shock, fatigue, and radiation damage effects in the solid structure behind the thin liquid 
surface layer will remain similar to these for a dry surface blanket, however. Fraas ${ }^{(3)}$ has proposed a thick, i.e., 1 meter, liquid lithium blanket for laser-pellet reactors. In this concept, termed the Blascon, the lithium flow is a open vortex, with the pellet and laser beam injected along the vortex axis. The liquid blanket is thick enough that most of the neutron energy is absorbed in the liquid, which minimized radiation damage effects in the surrounding solid structure. Since the liquid blanket remains in contact with the outer solid wall, however, shock pressures due to the extremely rapid heating can be propagated to the solid wall, with consequent structural degradation and farlgue. These effects can be reduced if a two-phase mixture of liquid and vapor is used in the blanket; this will attenuate shock waves to a much greater extent than a single phase liquid blanket.

A blanket which minimized the problems of radiation damage, shock, and fatigue for pellet fusion reactors is shown in Figure 1. A thick annular liquid cylinder, pouring down inside a cylindrical solid structure, forms the blast containment for the pellet explosion. The liquid wall is sufficiently thick to absorb the major part of the neutron energy, and is massive ennugh so that any outwards velocity imparted to it by the pellet explosion is small. The falling liquid cylinder is detached from the surrounding solid structure, so that shock waves cannot propagate to the solid structure. Although not shown in Figure 1, the top and bottom ends of the liquid cylinder can also be detached from any surrounding solid structure. Methods to achieve this are discussed later.

This concept, termed the BAM (Boiler and Moderator) reactor, appears to essentially eliminate radiation and blast damage to the blanket, since the 
blanket is now a detached, neutron absorbing thick liquid container surrounding the pellet. Liquid wall materials can be chosen so that the vapor pressure of the liquid is low enough that the propagation of the ion beam is not hindered. Also, liquid wall materials can be chosen that give high tritium breeding ratios. The principal remaining blanket problem appears to be the solid structure and conductors for the magnetic guide fields for focusing the heavy-ion beam (1f this turns out to be necessary). If such a structure penetrates the liquid wall, it would be subject to radiation and blast damage. However, since its diameter and length should be small compared to the dimensions of the BAM chamber, it can probably be replaced fairly frequently without serious effects on reactor availability and cost. However, it may not be necessary to have such a permanent guide structure projecting through the liquid wall; a guide structure outside the wall might be adequate, or each pellet might incorporate its own guide method, for example.

\section{General Features of the BAM Concept}

Figure 2 illustrates a typical BAM configuration. The liquid wall (e.g., $\mathrm{Pb}$, flibe, or $\mathrm{Li}$ ) is split into two zones--an inner spray zone which receives the initial impact of the pellet rays and plasma debris and degrades the fast neutron energy, and a thick, essentially continuous liquid wall which provides a high degree of attenuation of the neutron energy released by the pellet explosion. The surrounding solid structure (graphite in Figure 2) moderates the remaining neutrons, and the coolant (e.g., $\mathrm{Pb}$, flibe, or $\mathrm{Li}$ ) in the solid structure captures the neutrons and removes heat from the structure. I'he coolant in the solid structure will usually be the same as the 1iqu1d wall. Figure 3 is an idealized flowsheet for the BAM reactor, including some of its auxiliary systems (the accelerator system and pellet fabrication systems are notet shown). Thermal and lluw suvulling reservoirs will be required to minimize 
flow and temperature vartations in piping, pumps, and heat exchangers. Flow rates are typically on the order of $70 \mathrm{~m}^{3}$ per second after the liquid wall is established. A reservoir volume of $\sim 1000 \mathrm{~m}^{3}$ should provide sufficient smoothing; at a pellet explosion frequency of $1 / 3 \mathrm{H}_{z}$, approximately 4 explosions would occur during the holdup time of the reservoir.

Figure 3 shows three flow control functions at the top of the reaction chamber. With lithium and flibe liquid walls, pumping power requirements are sma11, and the liquid wall and spray zone flow will probably continue between. pellet explosions. With reaction chamber diameters of several meters, however, the pumping power requirements for the lead wall are an appreciable fraction ( $~ 10 \%$ ) of the reactor output, and it may be desirable to turn on the liquid. wall and spray zone flow approximately one second before the pellet explosion so as to minimize pumping power. This could be done nonmechanically by using a pulsed E-M valve. For example, the liquid flow could go through a pipe with a transverse magnetic field. Flow would be interrupted by applying a pulsed DC current to electrodes; the JXB force would then oppose the flow. In effect, the valve would be an intermittent liquid metal MHD pump, with the pump force applled opposite to the liquid flow direction. If small diameter reaction chambers are used, the interruption of the liquid wall flow between pellet explosions will not be needed since lead pumping power requirements will be sma11, even for continuous flow operation.

The third flow circuit in Figure 3 would control an intermittent-phased liquid flow from the top of the reaction chamber and would serve as a possible end closure option. The annular liquid wall protects the sides of the reaction chamber; however, the optimum length of the liquid wall will probably be approximately twice the diameter of the chamber. Using a much longer cylinder 
would increase pumping power losses, and would also require feed from an excessive number of levels in the side wall of the reaction chamber. [The designs discussed later, with a reaction chamber height of 10 meters, will probably require feed from 3 or 4 levels to ensure that the thickness variation of the liquid wall stays within acceptable limits (e.g., $\pm 20 \%$ of the average). If the height of the chamber were to further increase, the number of necessary feed levels would increase.] Assuming a height diameter ratio of $2 / 1$ for the reaction chamber and pellet explosions at midplane, the fluxes of X-rays, pellet debris, and neutrons at the ends will be approximately a factor of 4 less than the flux at the midplane sidewall. Even so, however, the reduced fluxes will probably still be too high to be able to cope with solid structures at the ends of the reaction chamber.

It appears relatively simple to close the top and bottom of the liquid wall annular cylinder, however, so that the pellet explosion is completely contained by a thick liquid she11. One method is to magnetically accelerate the ends of the falling liquid wall radially inwards (i.e., towards the axis of the annular liquid cylinder) shortly before the pellet explosion. As the liquid sheet is pinched closed at its top and bottom, the pellet is shot in and then ignited by the heavy-ion beam. For examp1e, a $2.5 \mathrm{kG}$ pulsed magnetic field generates an equivalent inwards pressure of $\sim 25$ atmospheres on the outer surface of the liquid cylinder. Assuming a pulse time of 10 milliseconds and assuming the most massive wall considered in this study (i.e., a $0.5 \mathrm{~m}$ lead wal1), the inwards velocity imparted to the wall by the magnetic pulse is 5 meters/sec and the ends close 200 milliseconds after the end of the magnetic pulse. The kinetic energy acquired by the liquid wall as a result of the pulse is $\sim 1.8 \mathrm{MJ}$, 
if there is a 1 meter long closure zone at each end. With various losses and inefficiencies, approximately $10 \mathrm{MJ}$ of stored energy would be required to effect end closure. This is quite small compared to tens of gigajoules of magnetic energy projected for toroidal theta pinch fusion reactors, for example, and should be relatively simple and cheap to supply.

An alternative end closure method is a time-phased intermittent flow of liquid from spray nozzles in the top surface of the reaction chamber. For a 10 meter high reaction chamber, flow would start 1.5 seconds before the pellet explosion, continue for approximately 0.25 second, stop for 1 second and then restart approximately 0.25 second before the pellet explosion. The top and bottom of the reaction chamber will then be effectively plugged by two thick discontinuous spray zones which absorb the impact of the X-rays and pellet debris as well as most of the incident neutron energy. There will be a clear zone approximately 8 meters high between these spray zones into which the pellet is injected just prior to its explosion.

Table 1 compares the relative advantages and disadvantages of the two end closure options. Both seem practical--the magnetic closure method is probably somewhat simpler technically, provided that stray magnetic fields do not affect ion beam focusing. Detailed system studies will probably be necessary to decide which method is better. For purposes of this study, however, we are primarily interested in the overall average response of the liquid wall sheet to a range of parametric operating conditions rather than a detailed response for a particular design. From this standpoint, either closure option will give essentially the same results.

An idealized model for the liquid wall response to the pellet explosion has been constructed. In this model the following sequence occurs: 
1. The pellet debris and X-rays impact on the surfaces of the drops in the inner spray zone that directly see the pellet (The debris and X-rays are assumed to travel in lines of sight from the pellet to the drops). The deposition of the X-rays and debris will be complete after a few microseconds. All of the momentum of the pellet debris is transferred to the inner layer of drops; these start to move radially outwards, transferring some momentum to adjacent drops through collisions. Eventually, all the drops in the inner spray zone collide with the continuous liquid wall and all of the outwards momentum absorbed fron the pellet debris is transferred to the liquid wall.

2. The energy absorbed by the inner drops from the pellet debris and $X-$ rays is assumed to be deposited on the surfaces of the drops that directly see the exploding pellet. All of this energy is assumed to result in vaporization of some fraction of the drops. Further, the predominant direction of motion of the resulting vapor is assumed to be radially inwards, i.e., towards the axis of the annular liquid cylinder. The inward momentum of the vapor created by the absorbtion of the pellet debris and $\mathrm{X}$-ray energy in the liquid drops is assumed to be balanced by an outward momentum of the unvaporized Iiquid drops. As. before, this outward momentum of the drops is assumed to be transferred to the Ilyuid wall when they collide with it.

3. The effect of rapid neutron heating in the liquid wall on its expansion velocity is not considered in this study. This effect will depend on the amount of neutron moderation in the pellet, the neutron slowing down time in the wal1, the wall density, and the degree of discontinuity in the liquid wall. A continuous liquid wall with internal neutron heating will have an induced liquid velocity due to thermal expansion of the liquid. The inner liquid surface (i.e., facing the pellet) would expand radially inwards, while the 
outer surface would expand radially outwards. If the inner liquid wall is discontinuous, i.e., a spray zone to condense vapor, it appears that the velocity induced by neutron heating should be reasonable, since most of the neutron energy will be deposited in the first $10 \mathrm{~cm}$ of the wall. If the outwards velocity from neutron heating should prove too high with a continuous outer liquid wall, it will be necessary to use a fully discontinuous dense spray zone for the entire 1iquid wall. This probably would increase the reaction chamber radius by $20-30 \%$, which should not significantly affect overall unit power cost. With drop sizes on the order of one $\mathrm{cm}$ in a dense spray wall, the neutron induced expansion velocity on the outer surface of the liquid wall would be a few centimeters per second. Detailed analysis of this effect will require knowledge of the energy spectrum of neutrons from the exploding pellet.

4. The vapor created inside the annular liquid wall cylinder, which is assumed to be effectively closed at both ends, exprts a pressure on the liquid wall and expands it outwards. The momentum of the liquid wall increases with time until the vapor recondenses. The pressure exerted by the vapor on the liquid wall is assumed to be determined by the amount of liquid vaporized (all of the pellet debris and X-ray energy is ahsorhed to create vapor) and the total volume inside the liquid wall shell. (The liquid drop surface temperature is assumed to be at a value that corresponds to the saturation temperature of the vapor at given pressure.) This idealization probably considerably overestimates the effect on the outwards expansion of the liquid wall, since there will be a strong pressure gradient between the inner layer of liquid drops and the inner surface of the continuous liquid wall due to recondensation of the vapor as it works its way through the liquid drop spray zone. If all vapor recondenses 
before reaching the continuous liquid wa11, the outward expansion resulting from the trapped vapor would be much smaller. With relatively thick and dense liquid spray zones, i.e., 5 or more $\mathrm{cm}$ at the equivalent of $100 \%$ density, this condition appears to be quite 1ikely. At this point, however, it appears advisable to be conservative, so the parametric analyses in this study assume that the inner liquid wall is subjected to the full pressure of the vaporized 1iquid.

5. The vapor is assumed to condense in a characteristic time, $\Delta t{ }_{w}$, Est1mates of condensation time can be made on the basis of the total surface area (drop and liquid wall) exposed to the vapor, and the time dependent temperature profile in drops suddenly subjected to a vapor at temperature $T_{v}$. When the sensible heat deposited in the drops by the condensing vapor equals the initial amount of absorbed energy, i.e., the energy of the pellet debris and X-rays, the vapor is assumed to be completely condensed. However, analyses show that even for relatively thin spray zones, the recondensation time is very short, i.e., much less than a millisecond. A nominal condensation time of 2 milliseconds is used in the parametric analyses described in this report, which also overestimates the effects of the vapor on the outwards expansion of the liquid wall.

The model thus yields three outward velocity components for the liquid wall (Table 2) resulting from: 1) absorption of pellet debris momentum, 2) reaction momentum from vapor produced by absorption of pellet debris and X-ray energy (rocket effect), and 3) momentum acquired when the trapped vapor causes the liquid wall to expand outwards. Figure 4 shows an idealized picture of the velocity of the liquid wall as a function of time after the pellet explosion. 
Table 3 shows the expressions for the three velocity components derived from the idealized model, and Table 4 defines the symbols used in the model. The total mass of the liquid wall is used in the analyses, and the computed velocities are averaged over the surface of the liquid wall. Local values probably exceed the average by at most a factor of two ( $L / D$ of the liquid wall cylinder is typically $2 / 1$ ).

The vapor condensation model assumes that full vapor pressure acts on the inner surface of the liquid wall for a time $\Delta t_{w}$, and then is zero for $t>\Delta t_{w}$. As discussed previously, this probably considerably overestimates the effect of the generated vapor on the outwards expansion of the liquid wall. Effects of Pellet Explosion on Liquid Wall

The exploding pellet imparts an outwards velocity to the liquid wall. The expanding liquid shell eventually strikes the surrounding solid structure so that the expansion velocity must be iimited to a few meters per second. There will be no damage to the liquid wall from either radiation or blast effects, and damage to the surrounding structure should be minimal. The liquid wall flow has to be re-established after the explosion, however. This study assumes a three second interval between pellet explosions in a given reactor chamber (there may be several chambers per accelerator), which corresponds to three free-fall transit times of the liquid wa11. Pumpout of noncondensible debris from the pellet explosion (He and perhaps unburned $D$ and $T$ ) should be complete in three seconds.

The three most likely materials for the liquid wall (for DT pellets--DD or other advanced fuel pellets would give a wider range of possible materials) are lithium, flibe $\left(\mathrm{LiF}_{2} \cdot \mathrm{BeF}_{2}\right)$, and lead, with a small concentration of $\mathrm{Li}$ in solution. Figure 5 shows the vapor pressure of these materials as a function of temperature. At $10^{-3}$ Torr, it has been estimated that the ion beam can 
probably travel $~ 10$ meters before it neutralized. (1) In the reactor chambers considered in this study the beam travels $\sim 3$ meters from the solid structure boundary to hit the pellet, and $10^{-3}$ Torr is probably an acceptable value of vapor pressure. Lead and flibe can operate above $500^{\circ} \mathrm{C}$ with this criterion, and lithium above $\sim 450^{\circ} \mathrm{C}$. At $10^{-4}$ Torr, operating temperatures of $\sim 550^{\circ} \mathrm{C}$ are possible with lead, $\sim 480^{\circ} \mathrm{C}$ with flibe, and $\sim 400^{\circ} \mathrm{C}$ with lithium. If beam neutralization is desired, the desired background pressures can be achieved by an inert gas filling.

Typical BAM reactor parameters for the three candidate liquid walls are shown in Table 5, based on the physical properties listed in Table 6 . The reactor conditions assumed are: pellet mass, $3 \mathrm{~g}$; pellet yield, $4 \mathrm{GJ}$; fraction of pellet yield as X-ray and plasma debris energy, $1 / 3$; $^{(1)}$ inner radius of liquid wall cylinder, $2.5 \mathrm{~m}$; length of liquid wall, $10 \mathrm{~m}$; thickness of liquid wall, $0.5 \mathrm{~m}$; and condensation, 2 milliseconds. The liquid wall is assumed to be closed at both ends prior to the pellet explosion. The weight of liquid wall vaporized differs widely for the three wall materials; however, the "moles vaporized is approximately the same, as well as the initial pressure inside the chamber, which is on the order of $10 \mathrm{~atm}$.

The $V_{1}$ velocity component is negligibly small for all three materlals because the momentum of the pellet debris is very low. The $\mathrm{V}_{3}$ component, which results from the pressure inside the liquid wall driving it outwards, is greater in all cases than the $V_{2}$ component, which results from the momentum imparted by the liquid as it vaporizes. As discussed previously, the $\mathrm{V}_{3}$ component is probably overestimated since the vapor should condense faster than indicated, and it should not exert its full force on the liquid wall, as assumed in the model. 
The total velocity, $\mathrm{V}_{\mathrm{T}}=\mathrm{V}_{1}+\mathrm{V}_{2}+\mathrm{V}_{3}$, is essentially a linear function of pellet yield since $\mathrm{V}_{1} \ll\left(\mathrm{V}_{2}, \mathrm{~V}_{3}\right)$, and $\mathrm{V}_{2}$ and $\mathrm{V}_{3}$ are linear, with yield. Figure 6 shows the dependence of $V_{T}$ on pellet yield for lithium, flibe, and lead. Lithium has a much higher outwards velocity than flibe or lead because of its low density. However, $\sim 90 \%$ of the total outwards velocity for lithium results from the $V_{3}$ component so that a less conservative model for estimating $V_{3}$ (i.e., faster condensation and a substantial pressure gradient through the liquid drop spray zone) would bring the expansion velocities for lead, 1ithium, and flibe much closer together.

The k1net1c energÿ carried by the expanding liquid wa11, rather than its velocity, probably gives a better measure of the potential damage to the surrounding solid structure when the liquid impacts on it. Figure 7 shows the kinetic energy in kilojoules $/ \mathrm{m}^{3}$ for the three candidate wall materials. Lithium has a much greater kinetic energy than flibe or lead because of its much higher expansion velocity. For lithium, a kinetic energy of $10 \mathrm{kilojoules/ \textrm {m } ^ { 3 }}$ corresponds to a fall distance of only 2 meters. Thus, the kinetic energy imparted by the explusiun to the outwardly expanding lithium, flithe, or lead, walis is mush less. than the kinetic energy acquired as it falls from the inlets at the top of the reaction chamber. Damage to the surrounding solid structure caused by impact of the expanding liquid wall should be negligible even for pellet yields of 10 gigajoules $\left(10^{1 \mathrm{U}}\right.$ Joules $)$.

Figures 8 - 11 show the effects of a range of reactor and pellet parameters on BAM reactor performance for a liquid lead wall of 0.5 meter thickness and pellet yields from 0 - 10 gigajoules. The mass of the pellet (Figure 8) has relatively little effect on the expansion velocity of the liquid wall over the range of 3 grams to 3 kilograms. This is a result of the very small momentum carried by the pellet debris. It seems unlikely that pellets would 
exceed $3 \mathrm{~kg}$ in weight so that the design of the BAM reactor chamber should not be significantly affected by the mass of the pellet.

The degree of neutron moderation in the pellet has a greater effect on reactor performance. Figure 9 shows the effect on expansion velocity for the maximum possible range of neutron moderation in the DT pellet, from the extreme of no moderation $\left(f_{p}=0.175\right.$, which accounts only for energy in $\alpha$ particles from the fusion reactions) to complete moderation $\left(f_{p}=1.0\right)$. Even with complete neutron moderation, which probably will not occur, the expansion velocity of the lead liquid wall is relatively low, i.e., 4.5 meters/second, at 10 gigajoules yield. This would be reduced substantially if more realistic estimates of the vapor condensation time were used. It thus appears that the reactor chamber design, though it will be somewhat affected by the degree of neutron moderation in the pellet, will not be significantly altered. For this . study the nominal value for the fraction of energy released as debris and $\mathrm{X}$-ray energy is taken as $1 / 3$. (1)

Figure 10 shows the effect of vapor condensation time on expansion velocity for the range of condensation times from 0 - 10 milliseconds. Reducing the condensation time to 0 milliseconds roughly cuts the expansion velocity in half, while increasing it to 10 milliseconds essentially triples it. Long condensation times, on the order of 10 milliseconds or greater, would have a significant effect on expansion velocity and chamber design. However, it appears very unlikely that such long condensation times will occur. The next section of this study examines the question of condensation time, and concludes that in fact the vapor probably will condense in a shorter period than 2 milliseconds rather than a longer period.

Figure 11 shows the effect of chamber size on the expansion velocity of the lead liquid wall for the range of pellet yields from 0 - 10 gigajoules. 
Chamber sizes larger than the nominal one, 2.5 meter radius and $10 \mathrm{~m}$ length, do not appear necessary since the liquid wall expansion velocity is small for the nominal size chamber. Smaller chambers yield higher expansion velocities which are still relatively reasonable. For example, a $1.5 \mathrm{~m}$ radius, $7.5 \mathrm{~m}$ long chamber results in a liquid wall expansion velocity of $\sim 5 \mathrm{~m} / \mathrm{sec}$ at a pellet yield of 10 gigajoules. Most of this expansion velocity results from the pressure of the vapor released inside the liquid wall chamber. If condensation time is considerably faster than the 2 millisecond value used in the analysis-which seems quite possible--the expansion velocity will be considerably smaller. Even smaller chambers may be feasible with fast condensation times. With a zero condensation time, for example, a 1.0 meter radius and 5 meter long liquid lead wall has an average expansion velocity of $\sim 4$ meter/sec after a 10 gigajoule pellet explosion.

The capital cost of a BAM fusion reactor should be relatively insensitive to the size of the liquid wall chamber for the range of dimensions considered in this study. The chamber is relatively simple; as with most magnetic fusion reactor designs, the balance of plant cost will predominate, which wi11 include the cost of the accelerator, piping, flow reservoirs, heat exchangers, turbine-generators, containment, and switch gear, etc. The solid structure for a $2.5 \mathrm{~m}$ radius, $10 \mathrm{~m}$ long liquid wall chamber should be a relatively minor part of the whole plant. Thus, there does not seem to be a marked incentive to press for smaller reaction chambers, except for the purpose of minimizing pumping power for the falling liquid wall. This point is discussed in more detail in a later section. There may be incentive for smaller chambers if lead is used to reduce recirculating power to the liquid wall pumps. 
Condensation of Vapor Produced by Pellet Explosions

The vapor produced by the pellet explosion appears to be responsible for the major portion of the outwards velocity of the liquid wall after a pellet explosion. As discussed previously, the vapor will start to recondense on the colder drops in the inner spray zone. It is assumed that the noncondensible gas portion (e.g., He, D, T) of the pellet debris is small enough that condensation is not hindered by mass transfer through a gas film around the drops. A g mole of noncondensible gases, for example, would result in a noncondensible gas density of $\sim 5 \times 10^{15}$ molecules $/ \mathrm{cm}^{3}$, which corresponds to a mean free path of $\sim 2$ millimeters. This would not appear to significantly hinder the vapor condensation rate in the liquid drops; the mean free path for collisions between atoms of the condensible vapor will be three orders of magnitide smaller.

The rate of condensation is assumed to be principally determined by the available surface area and thermal conductivity of the drops. In terms of internal temperature profile, the drops should be equivalent to flat planar surfaces. Condensation will be essentially complete when the thickness of the zone of appreciable temperature rise is still only a small fraction of drop radius.

Figure 12 shows the temperaluite profile (solid line) as a function of depth from the surface of the drop in units of $2(a t)^{\frac{1}{2}}(7)$ where (a) is the thermal diffusivity in the liquid drop and $(t)$ is the time after condensation starts. The heat transfer coefficient for the condensing vapor is assumed to be infinite. The temperature profile is assumed to be linear from the surface of the drop $\left(x^{*}=0\right)$ to a depth $\left(x^{* *}=2(a t)^{\frac{1}{2}}\right)$. The error introduced by this approximation is relatively sma11. When the sensible heat accumulated in this linear temperature zone equals the original thermal energy in the pellet debris 
and X-rays, the vapor is considered to be completely condensed. The neutron energy is deposited deep inside the liquid wall, and the local temperature increase that it causes is negligible (i.e., a few tens of ${ }^{\circ} \mathrm{K}$ ) compared to the local rise caused by vapor condensation in the inner spray zone.

Table 7 summarizes the equations relating vapor condensation time to drop area, pellet yield, and thermal conductivity. It is assumed that the vapor remains at a constant saturation temperature $\left(\mathrm{T}_{\mathrm{v}}\right)_{0}$ during the condensation process. As the vapor condenses, the saturation temperature will drop, but the change is relatively small even after most (e.g., 90\%) of the vapor has condensed. For purposes of this study, we assume the initial vapor saturation temperature to be $\sim 3000^{\circ} \mathrm{K}$, which corresponds to a vapor pressure of 35 atmospheres.

Figure 13 shows the drop surface area (exposed as an equivalent thickness of $0.8 \mathrm{~cm}$ diameter drops at $100 \%$ density factor) required to fully condense lead vapor in $0.25,1.0$, and 4.0 milliseconds for a range of pellet yields from 0 - 10 gigajoules (the fractional yield of pellet debris and X-ray energy is taken to be 1/3). The calculated condensation time is a smal1 frastion of a millisecond for reasonable thicknesses $(\mathrm{e} . \mathrm{g} ., \sim 5 \mathrm{~cm})$ of the inner spray zone. The nominal value of 2 milliseconds used in this study thus appears to be quite conservative. Since the vapor thermal speed is on the order of 500 meters/sec, it is 1ikely that condensation time will, be limited more by considerations of vapor flow through the spray than conductive heat transfer in the drops. Thie suggests that there probably will be a strong pressure gradient through the spray zone, with a low pressure of vapor at the surface of the continuous liquid wa11. The drops will be accelerated towards the liquid wall, but can only move 
a short distance during the condensation process. They will eventually transfer their acquired momentum to the continuous liquid wall by collisions. However, the drag coefficient of the drop should be low, on the order of 0.1 . Accordingly, the momentum acquired by the drops and transferred to the liquid wall should result in a much lower $V_{3}$ component than if the vapor exerted its full pressure on the continuous liquid wall. Tritium Breeding and Energy Absorption in the Liquid Wall Blanket

One-dimensional cylindrical neutron and gamma transport survey calculations were carried out for a range of liquid blanket designs using the ANISN code. $\mathrm{A} \mathrm{P}_{0} \mathrm{~S}_{4}$ approximation and ENDF/B-IV cross-sections were used to determine neutron fluxes, neutron heating, and tritium breeding ratios using a 100 group structure; gamma heating claculations used a 21 group structure.

The source neutrons were assumed to be at $14 \mathrm{MeV}$, with no moderation in the pellet, and the source was assumed to be a line (1 $\mathrm{cm}$ diameter) along the axis of the infinitely long one-dimensional cylindrical blanket. Dimensions of the blanket for the neutronics calculations correspond to the value at the midplane of the BAM reaction chamber, where the pellet explosion is assumed to occur.

The effect of a range of blanket parameters was examined, i.e., liquid wall thickness, solid structure thickness behind the liquid wall (a graphite solid structure was assumed, with a liquid coolant volume fraction of $4 \%$ in the graphite), and for lead liquid walls, the concentration of $\mathrm{Li}^{6}$ in lead. Only $\mathrm{Li}^{\dot{b}}$ was assumed to be effective in the analysis; the actual Li concentration can be calculated once the $\mathrm{Li}^{6} / \mathrm{Li}^{7}$ ratio is specified. A constant gap of $10 \mathrm{~cm}$ between the liquid wall and graphite structure was assumed. 
Figure 14 shows the tritium breeding ratio for lead $\left(1 \% \mathrm{Li}^{6}\right)$, 1ithium, and flibe liquid wall blankets of varying thicknesses. The graphite thickness is taken to be 0.5 meters for the lead and flibe blankets and 0.3 meters for the lithium blanket.

Lead walls have the highest breeding ratio, reaching a maximum of 2.3 at a wall thickness of $\sim 30 \mathrm{~cm}$. Lithium also has a high breeding ratio, approaching 2.0 , while flibe has a relatively low breeding ratio, i.e., $\sim 1.3$. If the $14 \mathrm{MeV}$ neutrons are strongly moderated in the pellet, the breeding ratio in flibe might drop below 1.0 .

The breeding ratio for the lead wall is affected by the $\mathrm{Pb} / \mathrm{Li}^{6}$ ratio. Figure 15 shows the effect of lead wall thickness and $\mathrm{Li}^{6}$ concentration on the tritium breeding ratio, with a graphite thickness of 0.5 meter. The breeding ratio drops with decreasing $\mathrm{Li}^{6}$ concentration, but is still quite high ( $\sim 1.6$ ) at a $\mathrm{Li}^{6}$ concetration of $0.02 \%$. Further reductions in $\mathrm{Li}^{6}$ concentration can bring the tritium breeding ratio to any desired value below 1.6 .

Figure 16 shows the tritium breeding ratio for liquid lead walls as a function of lead thickness and $\mathrm{Li}^{6}$ concentration, with a thinner $(0.3 \mathrm{~m})$ graphite zone outside the liquid lead wall. The breeding ratio is lower by $\sim 0.3$ with the thinner graphite zone. This is a result of reduced neutron moderation and increased leakage losses.

Figure 17 shows the fraction of fusion energy absorbed by the liquid in Lle 1lyuld wall and the accompanying liquid coolant in the $50 \mathrm{~cm}$ thick graphite zone behind the wall. With $50 \mathrm{~cm}$ thick lead and flibe liquid walls, only about $2 \%$ of the fusion energy is absorbed in the graphite structure; a somewhat thicker lithium wall, $\sim 80 \mathrm{~cm}$, is necessary to reduce fusion absorption energy in the 
solid structure to the same level. This corresponds to an average absorption energy of $\sim 11 \mathrm{~J} / \mathrm{cm}^{3}$ in the graphite structure, assuming a $10 \mathrm{GJ}$ pellet yield and a nominal chamber size (radius $=2.5 \mathrm{~m}$, length $=10 \mathrm{~m}$ ). The associated temperature rise after a pellet explosion is only about $0.4^{\circ} \mathrm{C}$, which should not cause temperature/stress cycling problems. Pumping Power Requirements for Liquid Walls

Figure 18 shows pumping power requirements for the lead, lithium, and flibe liquid walls as a function of pellet yield. A recirculating power of $6 \%$ (pumping power/reactor thermal power) is taken as the practical limit for the BAM reactor. This corresponds to a recirculation of $15 \%$ of the gross electric power produced for a thermal cycle efficiency of $40 \%$. In this calculation, no credit is taken for pressure recovery by deceleration of the falling liquid wall. The kinetic energy of the falling liquid is taken to be converted to thermal energy in the liquid, which is then put back into the $\sim 40 \%$ efficient thermal power cycle, together with losses due to pump inefficiencies. The electrical energy obtained in this fashion tends to compensate for mechanical inefficiencies in the pumps for the liquid wall. [With a $40 \%$ thermal cycle efficiency and a mechanical pump efficiency of $60 \%$, net pump power requirements equal the ideal assuming a $100 \%$ efficient pump.] A 100\% pump effirienry has been used in the analysis for Figure 18. Lithium and flibe liquid walls have quite low reciruclating pump power requirements. A full flow liquid lead wall (liquid flow is on for $100 \%$ of the time) with a nominal chamber size, on the other hand, has acceptable pump power requirements only for pellet yields greater than $4 \mathrm{GJ}$. Intermittent flow liquid lead walls, i.e., flow for $50 \%$ of the time, or full flow walls in small reactor chambers (e.g., $r_{w}=1.5 \mathrm{~m}, \mathrm{~L}_{\mathrm{w}}=7.5 \mathrm{~m}$ ) have acceptable pumping power requirements for pellet yields greater than 2 GJ. It thus appears that lead walls do have acceptable pumping power requirements over a large fraction of the practical reactor 
parameter space, while lithium and flibe walls have acceptable pumping requirements over virtually all of reactor parameter space.

Summary and Conclusions

Thick liquid wall blankets appear to be of great promise for heavy ion pellet fusion reactors. They avoid the severe problems of intense radiation and blast damage that would be encountered with solid blanket structures. The liquid wall material can be chosen so that its vapor pressure at the working temperature of the power cycle is well below the value at which it might interfere with the propagation of the heavy ion beam. The liquid wall can be arranged so that it does not contact any surrounding solid structure when the pellet explosion occurs, including the ends. The ends can be magnetically closed just before the pellet explosion, or a time phased flow can be used, which will leave a clear central zone into which the pellet is injected.

Parametric analyses comparing three candidate liquid wall materials were carried out. The three materials were lithium, flibe, and lead (with a low concentration of disolved 1ithium). Lead appeared to be the best choice for the liquid wall, although any of the three should allow a prartiral reactor system. The parametric analyses examined the effects of pellet yield ( 0 to 10 GJ), pellet mass ( $3 \mathrm{~g}$ to $3 \mathrm{~kg}$ ), liquid wall thickness (10 $\mathrm{cm}$ to $80 \mathrm{~cm}$ ), vapor condensation time ( 0 to 10 milliseconds), degree of neutron moderation in the pellet (none to 100\%), liquid wall chamber size (radius of 1.5 meters to 4 meters), $\mathrm{Pb} / \mathrm{Li}^{6}$ ratio (100 to 5,000), and thickness of graphite mnderating, zone behind the liquid wall.

A number of important general conclusions emerged from the parametric analysis: 
- Lead has a much lower expansion velocity and kinetic energy following a pellet explosion than lithium or flibe does.

- Lead liquid wall reactor chambers can be much smaller than lithium or flibe for a given pellet yield.

- Pellet yields up to $10 \mathrm{GJ}$, and probably considerably larger, can be readily accommodated with a lead liquid wall chamber.

- Condensation time of the vapor produced by the absorption of plasma debris and X-ray energy is a important factor determining expansion velocity of the liquid wall.

- A relatively thin (in the order of $10 \mathrm{~cm}$ ) Inner spray zone of small drops ( $0.5 \mathrm{~cm}$ in diameter) should result in very rapid condendation (within a time on the order of 1 millisecond) of the vapor.

- The mass of the pellet has only a very small effect on the expansion velocity of the liquid wall.

- The degree of neutron moderation in the pellet is an important factor in determining liquid wall expansion velocity after a pellet explosion, but practical reaction chambers could be built even with complete conversion of the neutron energy to plasma debris and $\mathrm{X}$-ray energy.

- Chamber sizes down to 1.5 meter in radius with liquid lead walls appear practical even for pellet yields of $10 \mathrm{GJ}$.

- Tritium breeding ratios are highest for lead walls and substantially exreed 2. With lithium walls, the breeding ratio approaches 2 , but with flibe walls it is relatively low, i.e., 1.25 .

- Almost all, i.e., $298 \%$, of the fusion energy release is produced directly in the liquid wall or on the coolant that circulates through 
the graphite structure behind the liquid wall for a liquid wall thickness of $\sim 0.5$ meter.

- If thick liquid walls are desired to minimize radiation damage to surrounding solid structures, only with lead walls can the tritium breeding ratio be adjusted to any desired value by changing the $\mathrm{Li}^{6}$ concentration in lead. Lithium and flibe walls will breed considerably more tritium than is needed to run the reactor, and the surplus tritium produced will have to be stored for long periods until it decays to $\mathrm{He}^{3}$.

- Pumping power requirements for the lithium and flibe walls are very small, but become appreciable, i.e., $10 \%$ of power output for lead walls if the reaction chamber is larger and the pellet yield is small (< $4 \mathrm{GJ}$ ). Pumping power requirements for lead walls can be reduced by- using full flow only when a pellet explosion is about to occur.

Acknowledgments

The authors wish to express their grateful appreciation to Ms.'s Carolyn Eterno and Pamela Walton for typing and preparation of this report, and to Mr. Stan Majeski for preparation of the drawings.

\section{$\underline{\text { References }}$}

1. ERDA Summer Study of Heavy Ions for Inert1al Fusion, LBL-5543, (July 19-30, 1976) [Report Date December 1976].

2. Booth, L. A., Nuc. Eng. Des., 24, 263 (1973). 
3. Fraas, A. P., et. al., Analytical and Experimental Investigation of the Blascon Energy Conversion System for Laser Fusion Reactors, ASME Paper 72WA Ener/1, New York, (Nov. 26-30, 1972).

4. Nesmeyanov, A. N., Vapor Pressure of the Chemical Elements, Elsevier, New York, (1963).

5. Lyon, R. N., ed., Liquid Metals Handbook, NAVEXOS, pp. 733, AEC, (June 1952).

6. Mills, R. G., ed., A Fusion Power Plant, Matt 1050, Princeton Plasma Physics Laboratory, (August 1974).

7. Arpaci, V. S., Conduction Heat Transfer, pp. 302, Addison-Wesley, New York (1966). 
PULSED MAGNETIC DRIVE AT ENDS

- ADVANTAGES

- AVOIDANCE OF INTERMITTENT FLOW CONTROLS

- PREVENTION OF VAPOR ESCAPE AT ENDS (?)

- Disadvantages

- POSSIBLE DEFOCUSING OF ION BEAM

INTERMITTENT FLOW AT ENDS

- ADVANTAGES

- AVOIDANCE OF MAGNETIC rIELd brHECIS

- disadvantages

- NEED FOR INTERMITTENT FLOW CONTROLS FOR PORTION OF LIQUID FLOW $\left(R<R_{W}\right)$ - MECHANICAL OR MAGNETIC VALUES REQUIRED

IABLE 2

LIQUID WALL VELOCITY COMPONENTS

$V_{1}$ - GENERATED BY ABSORPTION OF MOMENTUM OF IMPACTING PLASMA DEBRIS

$V_{2}$ - GENERATED BY MOMENTUM OF EVAPORATING MATERIAL FROM LIQUID NALII

$V_{3}$ - GENERÁItU BY HKESSURE OF VAPOR TRRAPPED INSIDE LIQUID WALL 


\section{PARAMETERS AFFECTING $v_{1}, v_{2}$, AND $v_{3}$}

IABLE ;

\section{VELOCITY CCMPOMEST EXPRESSIONS}

$$
V_{1} \quad=(M V)_{P} / M_{L W}=\frac{\left[2 M_{P} E_{p} F_{P}\right]^{\frac{1}{2}}}{M_{L W}}
$$$$
V_{2}=\frac{E_{P} f_{P} V_{T H}}{2 \lambda_{W} M_{L W}}
$$

$v_{3}=\int_{J}^{T} \frac{P_{V}(T) d T}{\Delta R_{W}{ }^{P} w}$

$P_{V}(T)=\left[\frac{E_{P} E_{p}}{\lambda_{W}\left(M_{W}\right)}\right]\left[\frac{R_{V}}{R^{2} R_{W}^{2} W_{W}}\right] \quad F_{N C}(T)$

$f_{\text {NC }}=$ FRACTION OF VAPOR NOT CONDENSED AT TIME. $T$

\section{CONDENSAT ION MODEL}

$\begin{array}{lll}\mathrm{f}_{\mathrm{NC}} & =1 & 0 \leq t \leq \Delta t_{W} \\ \mathrm{f}_{\mathrm{NC}} & =0 & \Delta t_{W} \leq t \leq t\end{array}$

$M_{P}$ - MASS OF PELLET, KG

$E_{p}$ - PELLEt ENERG YIEL, J

f P - fRACTION OF PELLET ENERGY. AS DEBRIS AND X-ray ENERGY

$R_{W}$ - INNER RADIUS OF LIQUID HALL, $M$

Lw - EQUivalent LENGTH OF LIQUID WALL, $M$

$\Delta R_{W}$ - THICKNESS OF LIQUID WALL, $M$

$\Delta R_{G}$ - THICKNESS OF GAP BETHEEN LIQUID HALL AND SOLID STRUCTURE, $M$

$R_{D}$ - RADIUS OF DROPS IN SPRAY CONDENSATION LAYER, $M$

$\triangle R_{D}$ - EQUIVALENT THICKNESS OF SPRAY CONDENSATION LAYER, $M$

${ }^{\circ} W$ - DENSITY OF LIQUID HALL, KG/M ${ }^{3}$

$\lambda_{w}$ - heAT OF VAPORIZATION OF LIQUID WALL, J/KG

$V_{T M}$ - THERMAL SPEED OF VAPOR, M/SEC.

$K_{W}$ - THERMAL CONDUCTIVITY OF LIQUID HALL, W/MK

$T_{v}$ - TEMPERATURE OF VAPOR, ${ }^{\circ} \mathrm{K}$

$M_{w}$ - MASS OF LIQUID WALL, $k G\left[E\left(R_{w}, L_{w}, \Delta R_{w}, P_{w}\right)\right]$

$\Delta t_{W}$ - CONDENSATION TIME FOR VAPOR INSIDE LIQUID, SEC $\left[E\left(R_{D}, \Delta R_{D}\right.\right.$, $\left.E_{p}, f_{p}, R_{w}, L_{w}, \lambda_{w}, K_{w}\right]$

$P_{v}$ - INITIAL PRESSURE OF EVAPORATEd LIQUID INSIDE LIQUid WALL $\left[E\left(E_{p}, f_{p}, T_{v}, R_{w}, L_{w^{\prime}} \lambda_{w}\right)\right]$ 
IABLE 5

TYPICAL BAM REACTOR PARAMETERS

CONDITIONS: $\begin{aligned} \mathrm{E}_{\mathrm{P}} & =1 / 3 \\ R_{W} & =2.5 \mathrm{M} \\ \Delta R_{W} & =0.5 \mathrm{M} \\ E_{\mathrm{P}} & =4 \mathrm{GJ} \\ L_{W} & =10 \mathrm{M} \\ \Delta T_{W} & =2 \mathrm{MILLISEC} \\ \text { LEAD } & \text { LITHIUM }\end{aligned}$

$\begin{array}{llll}\text { DENSITY, KG/M } & 10,000 & 500 & 1900 \\ M_{L W^{\prime}} \text { KG } & 1.1 \times 10^{6} & 5.51 \times 10^{4} & 2.09 \times 10^{5} \\ { }^{{ }^{\prime} W^{\prime}} \mathrm{J} / \mathrm{KG} & 9.4 \times 10^{5} & 22.7 \times 10^{6} & 3.1 \times 10^{6} \\ \text { KG VAPORIZED } & 1415 & 58.6 & 214.5 \\ \text { G MOLES VAPORIZED } & 6830 & 8470 & 5810 \\ P_{V}(t=0), \text { ATM } & 8.65 & 11.4 & 7.37 \\ V_{T H^{\prime}} \text { M/SEC } & 450 & 2600 & 1120 \\ V_{1}, M / S E C & 2.6 \times 10^{-3} & 0.051 & 0.0135 \\ V_{2}, M / S E C & 0.289 & 1.38 & 0.57 \\ V_{3}, M / S E C & 0.346 & 9.12 & 1.55 \\ V_{T}, M / S E C & 0.638 & 10.55 & 2.13\end{array}$

IABLE

PHYSICAL PROPERTIES OF CANDIDATE LIQUID WALL MATERIALS

\begin{tabular}{|c|c|c|c|}
\hline & $\operatorname{LEAD}^{4,5}$ & Lенния 4,5 & ELIBE $(A)^{6}$ \\
\hline DENSITY, KG $M^{-3}$ & 10,000 & 500 & 1900 \\
\hline $\begin{array}{l}\text { HeAt of Vaporazation, } \\
\text { I KG-1 }\end{array}$ & $9.4 \times 10^{5}$ & $2.27 \times 10^{7}$ & $3.1 \times 10^{6}$ \\
\hline $\begin{array}{l}\text { HeAt of Varóiazation, } \\
J(G \text { mOLE })^{-1}\end{array}$ & $1,95 \times 10^{5}$ & $1,58 \times 10^{5}$ & J.15 $\times 10^{5}$ \\
\hline $\begin{array}{l}\text { MOLECULAR SPEED OF VAPOR } \\
\text { AT } 3000^{\circ} \mathrm{K} \text {, M SEC-1 }\end{array}$ & $4.5 \times 10^{2}$ & $2.6 \times 10^{3}$ & $8.0 \times 10^{2}$ \\
\hline $\begin{array}{l}\text { THERMAL CONDUCTIVITY, } \\
\text { H } \mathrm{CH}^{-1} \mathrm{nK}^{-1}\end{array}$ & 0.150 & 0.376 & $8 \times 10^{-3}$ \\
\hline $\begin{array}{l}\text { HeAT CAPACITY, } \\
J_{G}-1{ }^{0} \mathrm{~K}-1\end{array}$ & 0.155 & 4.18 & 2.35 \\
\hline $\begin{array}{l}\text { VAPOR PREssure at } \\
500^{\circ} \mathrm{C} \text {. ToRR }\end{array}$ & $2 \times 10^{-5}$ & $4 \times 10^{-3}$ & $2 \times 10^{-5}$ \\
\hline
\end{tabular}

(A) FLibe is assumed to Vaporize as a mixture of gaseous species WITH A MEAN MOLECULAR WEIGHT OF 37.1 (46.9\% LIF, 53.1\% BeF 2 ) 
EXACI SOLUTION

$$
\left(\frac{T-T_{0}}{T_{0}-T_{\infty}}\right)_{x}=\operatorname{ERFC} \frac{x}{2(A T)^{\frac{1}{2}}}
$$

APPROXIMATE SOLUTION

$$
\left(\frac{T-T_{\infty}}{T_{0}-T_{\infty}}\right)_{x}=\frac{X}{2(A T)^{\frac{1}{2}}} \quad \text { FOR } 0 \leq X \leq 2(A T)^{\frac{1}{2}}
$$

BELALLON BETWEEN CONDENSALLON LUME AND DROP AREA

$$
\begin{aligned}
& X^{*}=2(A T)^{\frac{1}{2}} \\
& \Delta T_{X}=\frac{X}{X^{*}}\left(\Delta T_{\text {MAX }}\right)=\frac{X}{X^{*}} \frac{\overline{\Delta T_{X}}}{2}=\frac{X}{X^{*}} \frac{T_{\infty}-T_{0}}{2}
\end{aligned}
$$

FOR $100 \%$ CONDENSATION,

$$
\begin{aligned}
& \overline{\Delta T_{X}} X^{*}\left(C_{P}\right)_{D} A_{\text {SPRAY }}=E_{P} E_{P}={ }_{W} M_{V A P O R} \\
& A_{\text {SPRAY }}=\left(\frac{3 \Delta R_{D}}{R_{D}}\right)_{A_{L W}} \\
& \Delta T_{W}\left(\frac{E_{P} f_{P}}{A_{S P R A Y} \Delta T_{\text {MAX }}}\right)^{2} \frac{1}{K_{D}\left(C_{P}\right)_{D}}
\end{aligned}
$$

$T_{0}=$ Initial TEMPERATURE; $T_{\infty}=$ VAPOR TEMPERATURE

$X=$ DISTANCE INTO DROP FROM SURFACE, CM.

$T=T_{I M E}, \operatorname{SEC}$

$A=$ Thermal Diffusivity, $\mathrm{CM}^{2} / \mathrm{SEC}$

$\triangle R_{D}=$ DROP RADJUS, $C M$

$R_{D}=$ Equivalent RaDial thickNess OF SPRAY ZONE, CM

$A_{\text {LW }}=$ INNER AREA OF CONTINUOUS LIQUID WALL, $\mathrm{CM}^{2}$

$K_{D}=$ THERMAL CONDUCTIVITY OF DROP, $W / \mathrm{CM}^{0} \mathrm{~K}$

$\left(C_{P}\right)_{D}=$ HEAT CAPACITY OF DROP, $J / \mathrm{CM}^{3}{ }^{3} \mathrm{~K}$ 


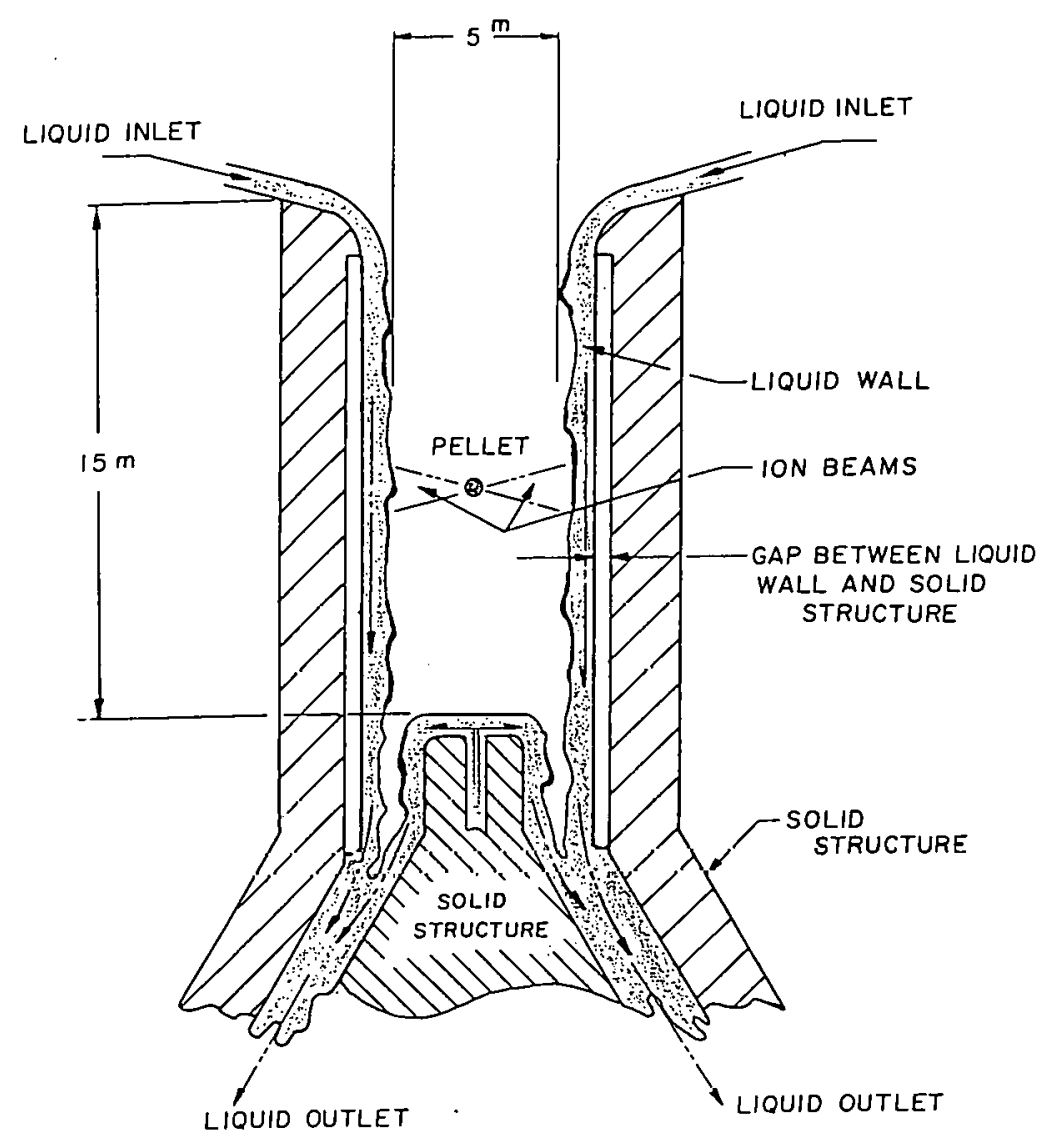

Figure 1. Liquid wall. boiler for fusion pellet systems.

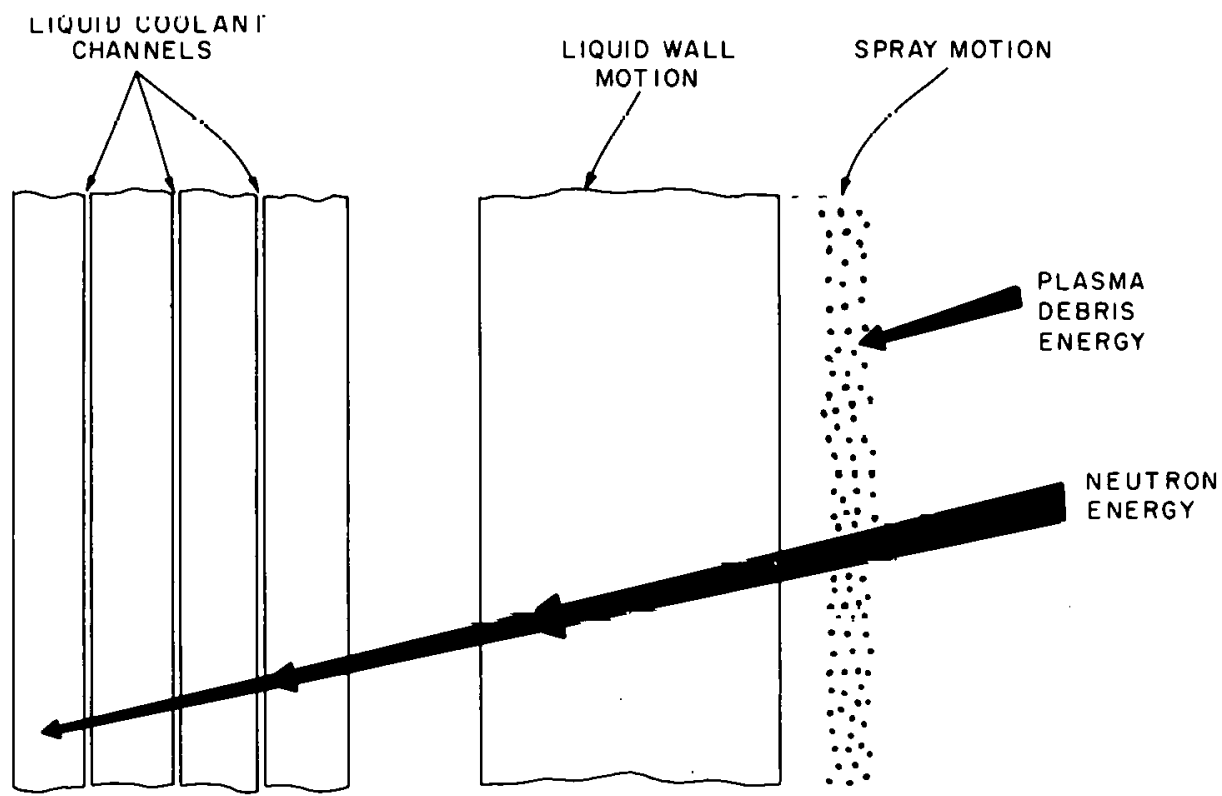
SOLID GRAPHITE WALL
GAP
LIQUID WALL
INNER SPRAY WALL
(TYP $0.5 \mathrm{~m}$ ) (TYP $0.3 \mathrm{~m}$ )
(TYP $0.5 \mathrm{~m}$ )
(TYP $0.3 \mathrm{~m}$ )

Figure 2. Detail view of liquid wall. 


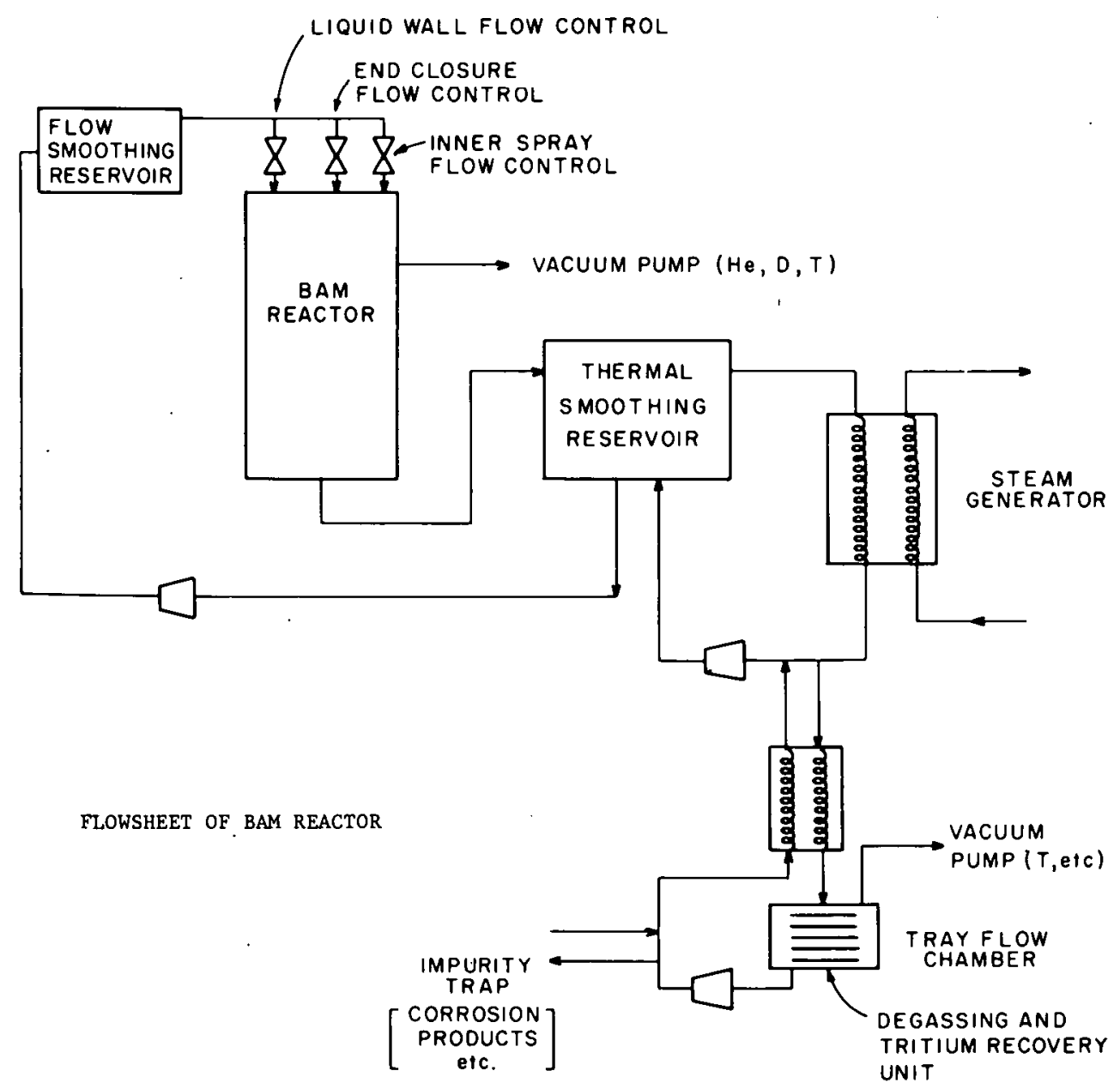

Figure 3. Flowsheet of BAM Reactor. 


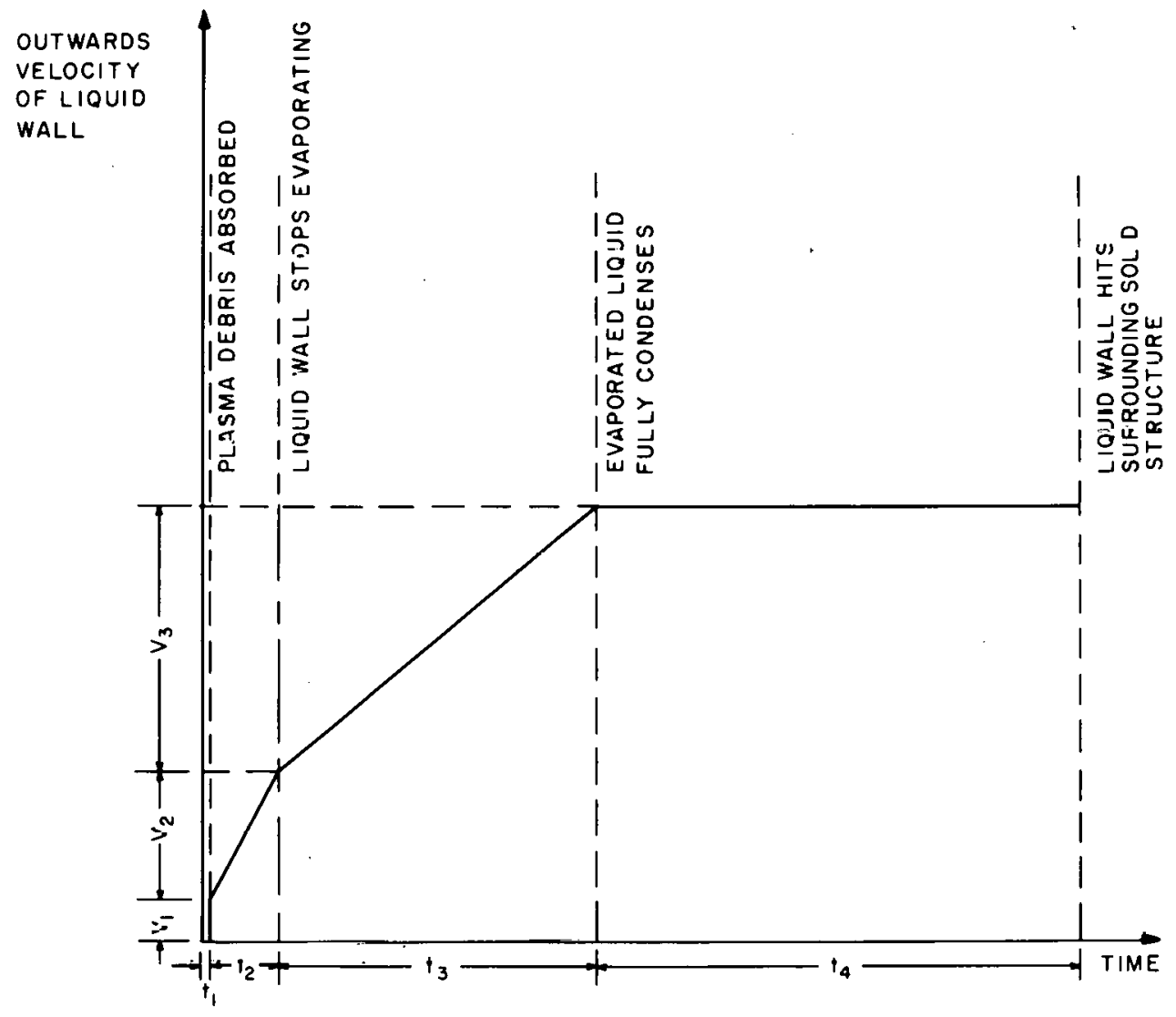

IOEALIZED EXPANSION OF LIQUID WALL AFTER PELLET EXPLOSION

F1gure 1. Idealiecd cxpansion beliavius of llyuld wall after pellet explosion. 


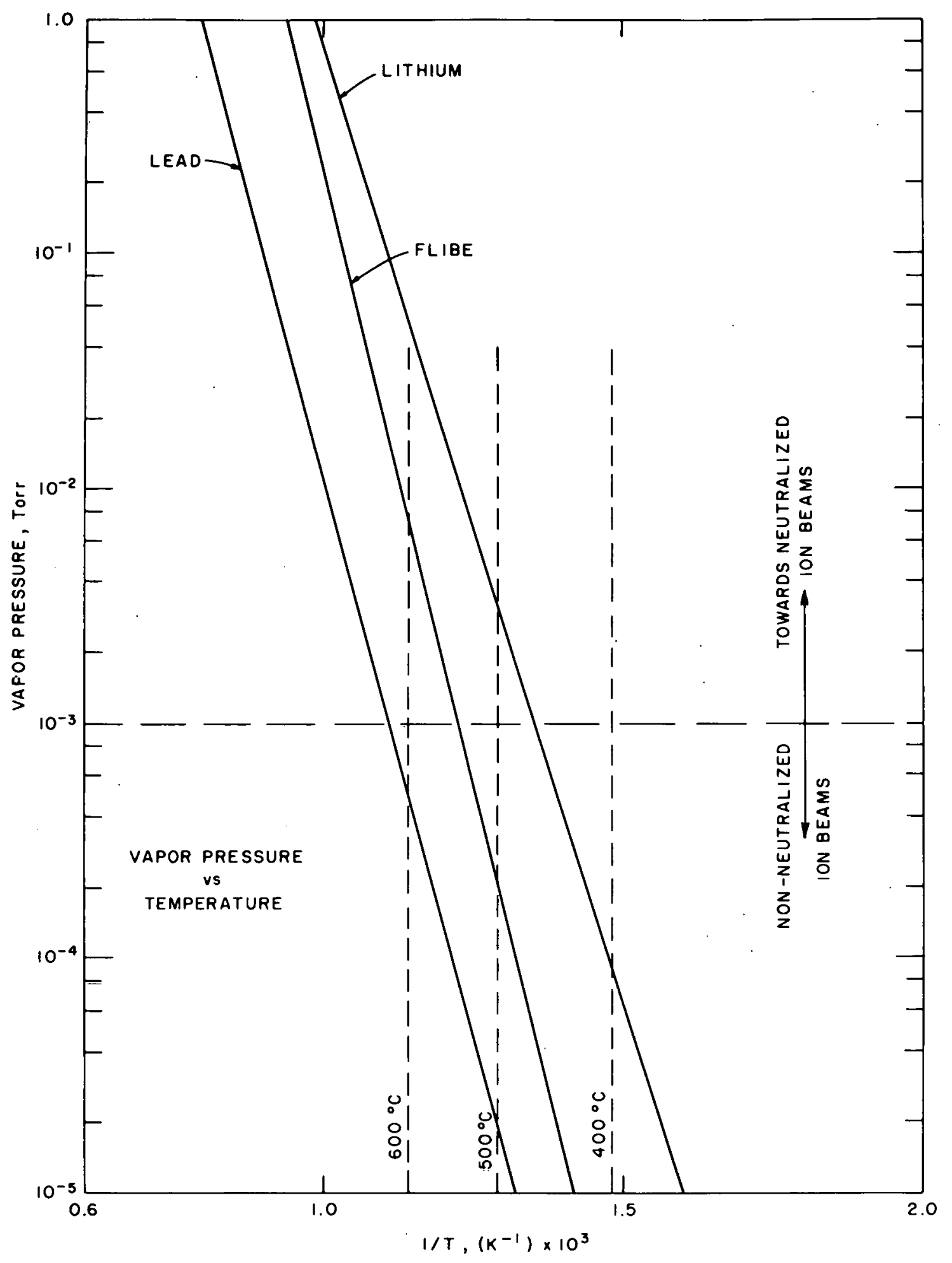

Figure 5. Vapor pressure of candidate liquid walls as a function of temperature. 


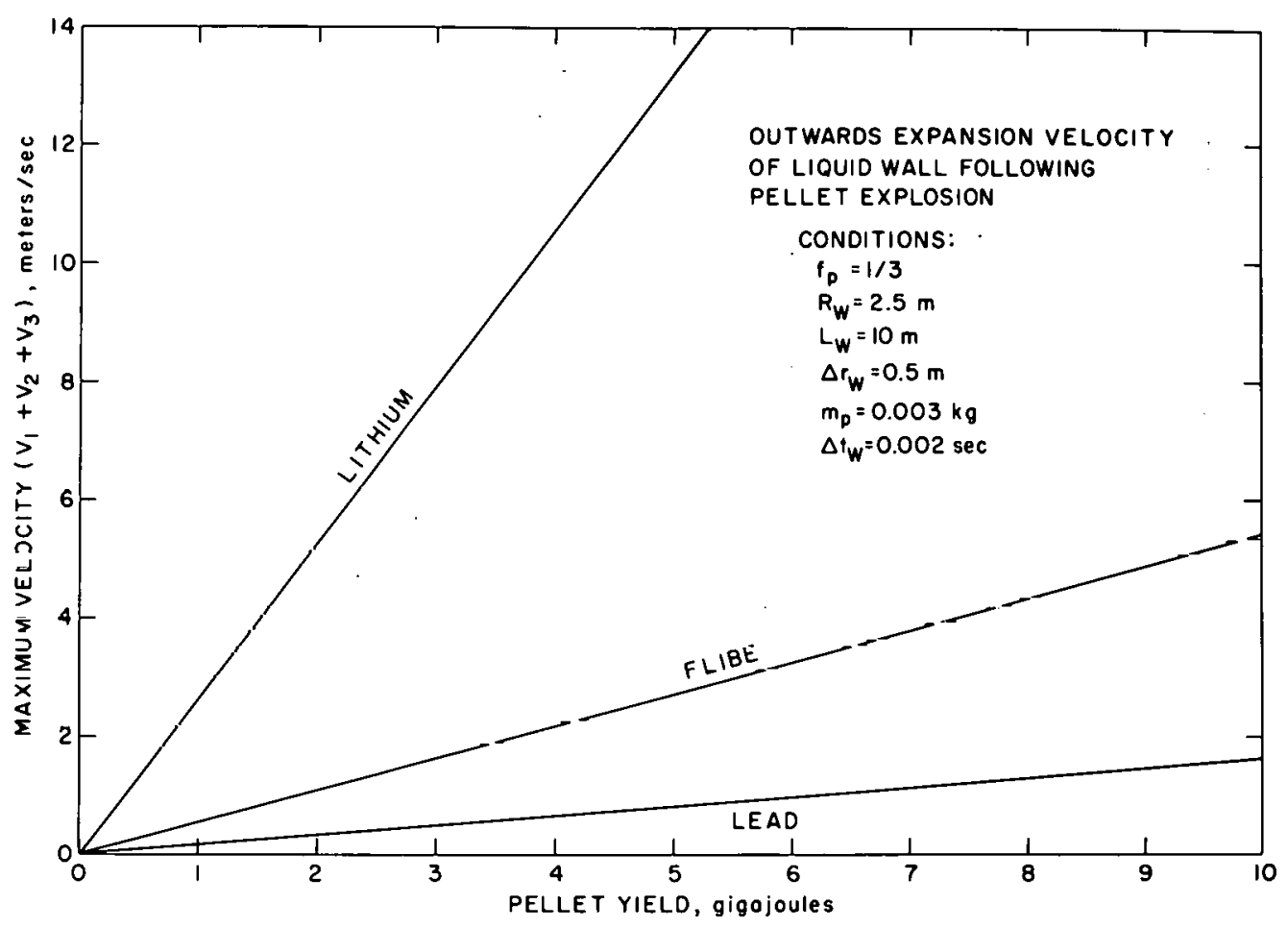

Figure 6. Outwards expansion velocity of liquid wall vs. pellet yield, for different candidate liquid walls.

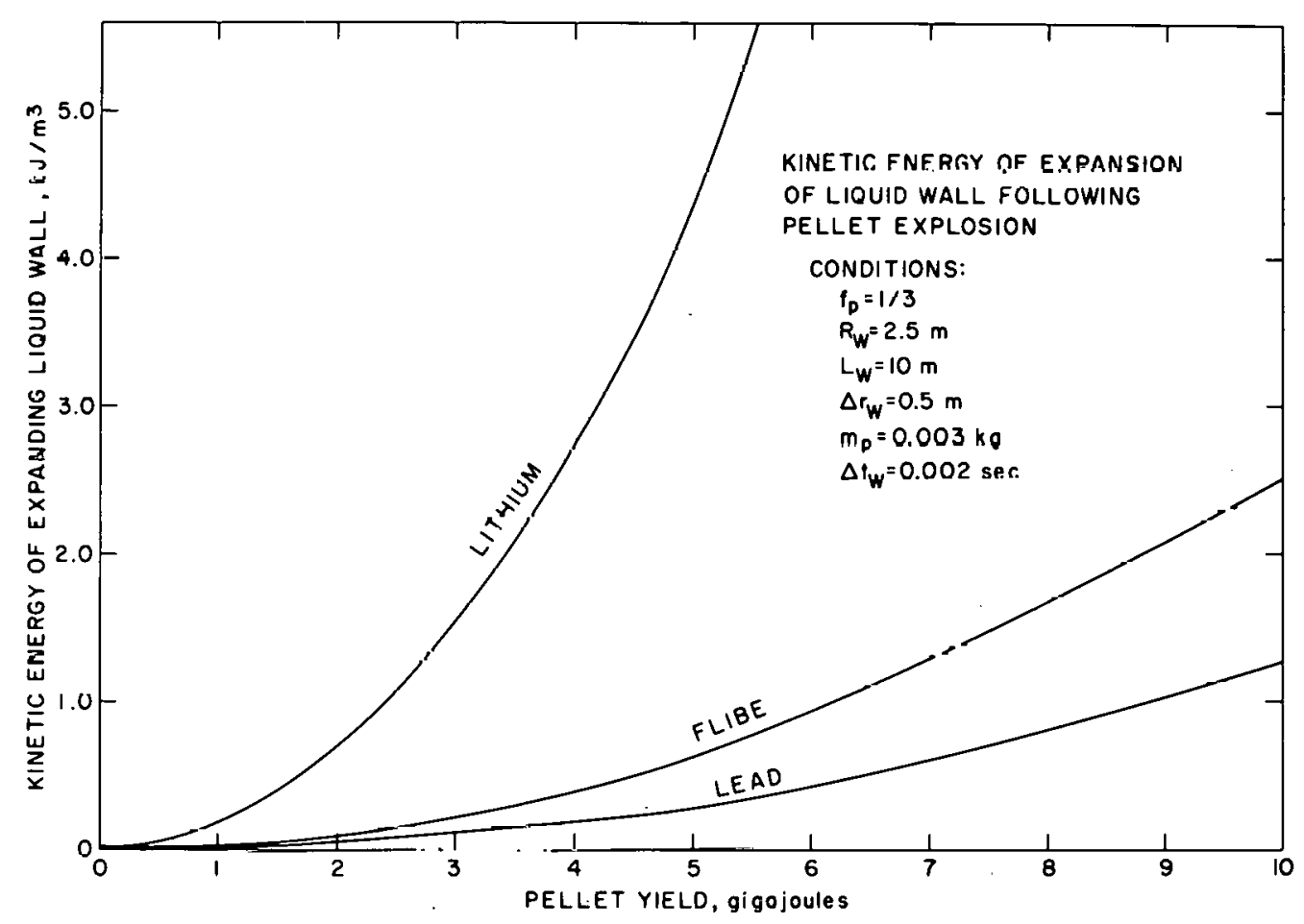

Figure 7. Kinetic energy of expansion of liquid wall vs. pellet yield, for different candidate liquid walls. 


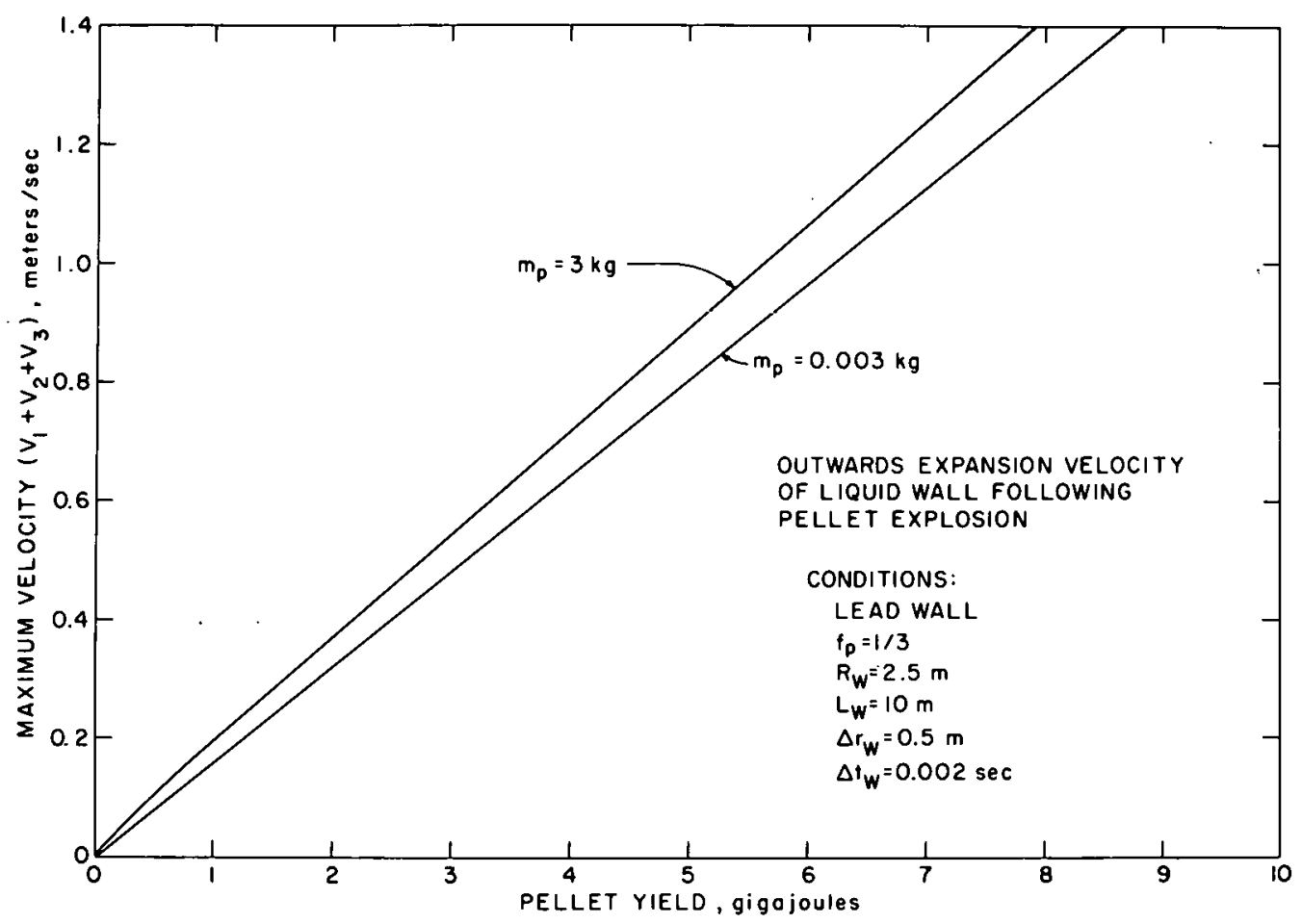

Figure 8. Expansion velocity of liquid lead wall vs. pellet yield, for different pellet masses.

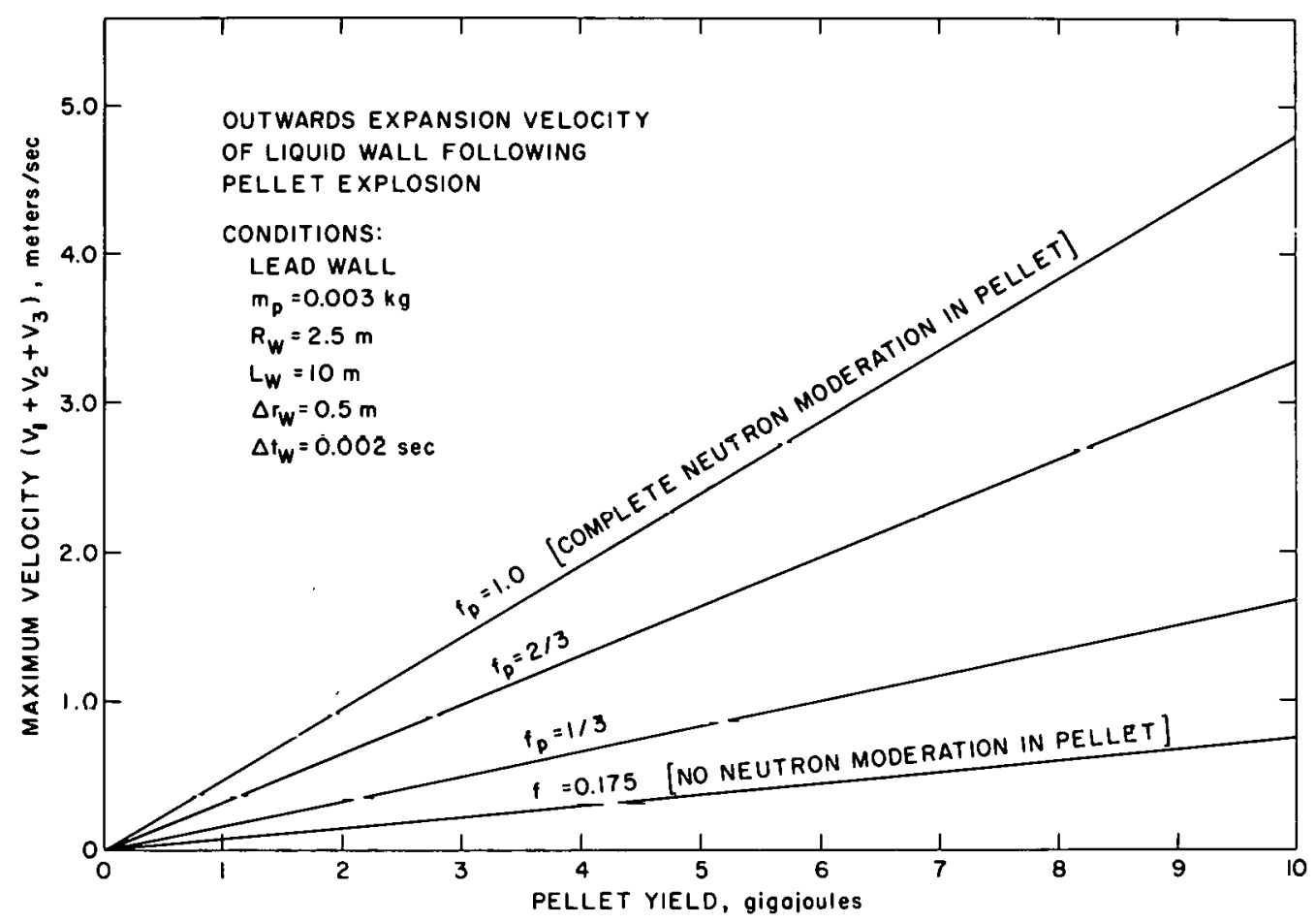

Figure 9. Expansion velocity of liquid lead wall vs. pellet yield, for different degrees of neutron moderation in pel1et.. 


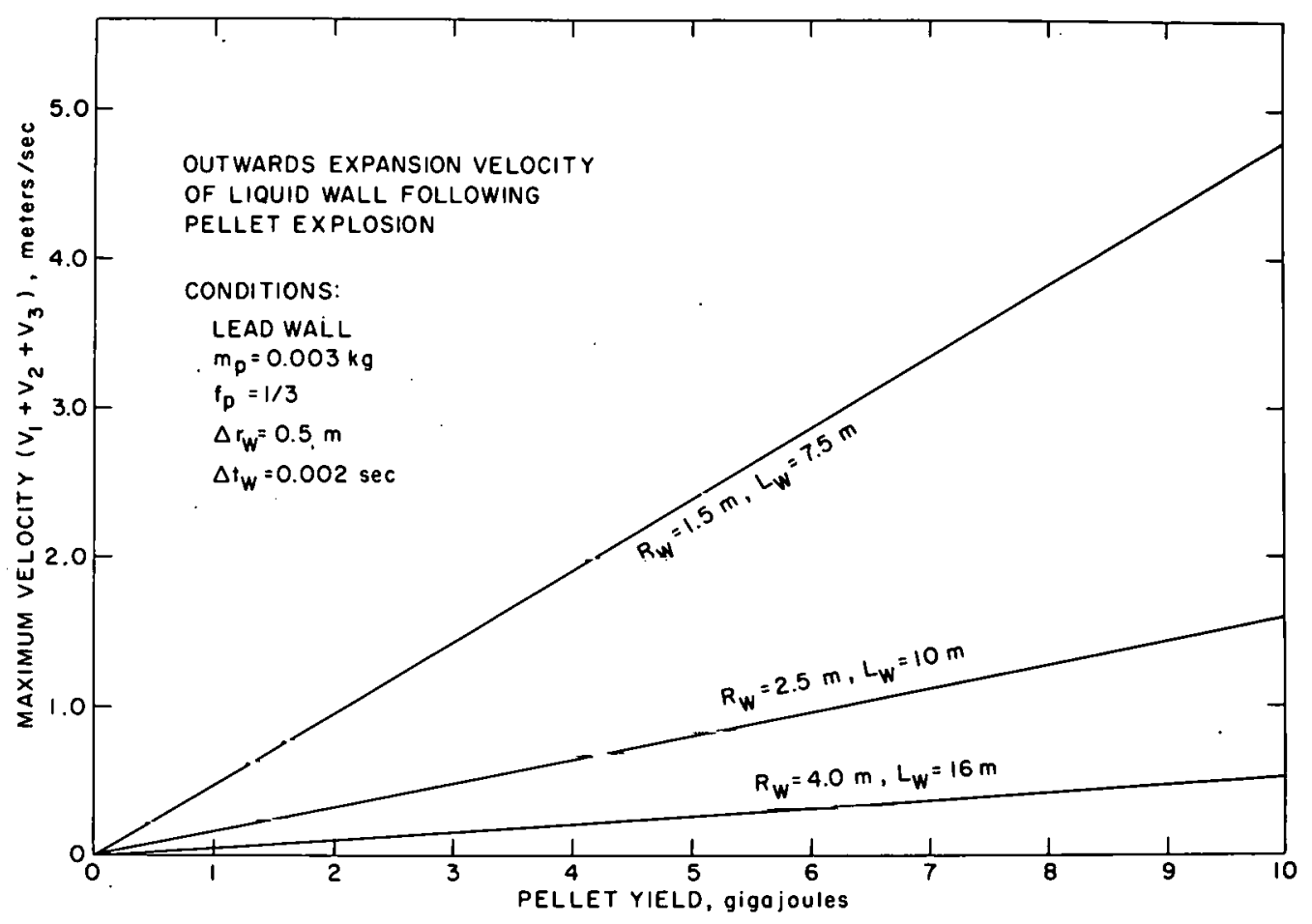

Figure 10. Expansion velocity of liquid lead wall vs. pellet yield, for different vapor condensation times.

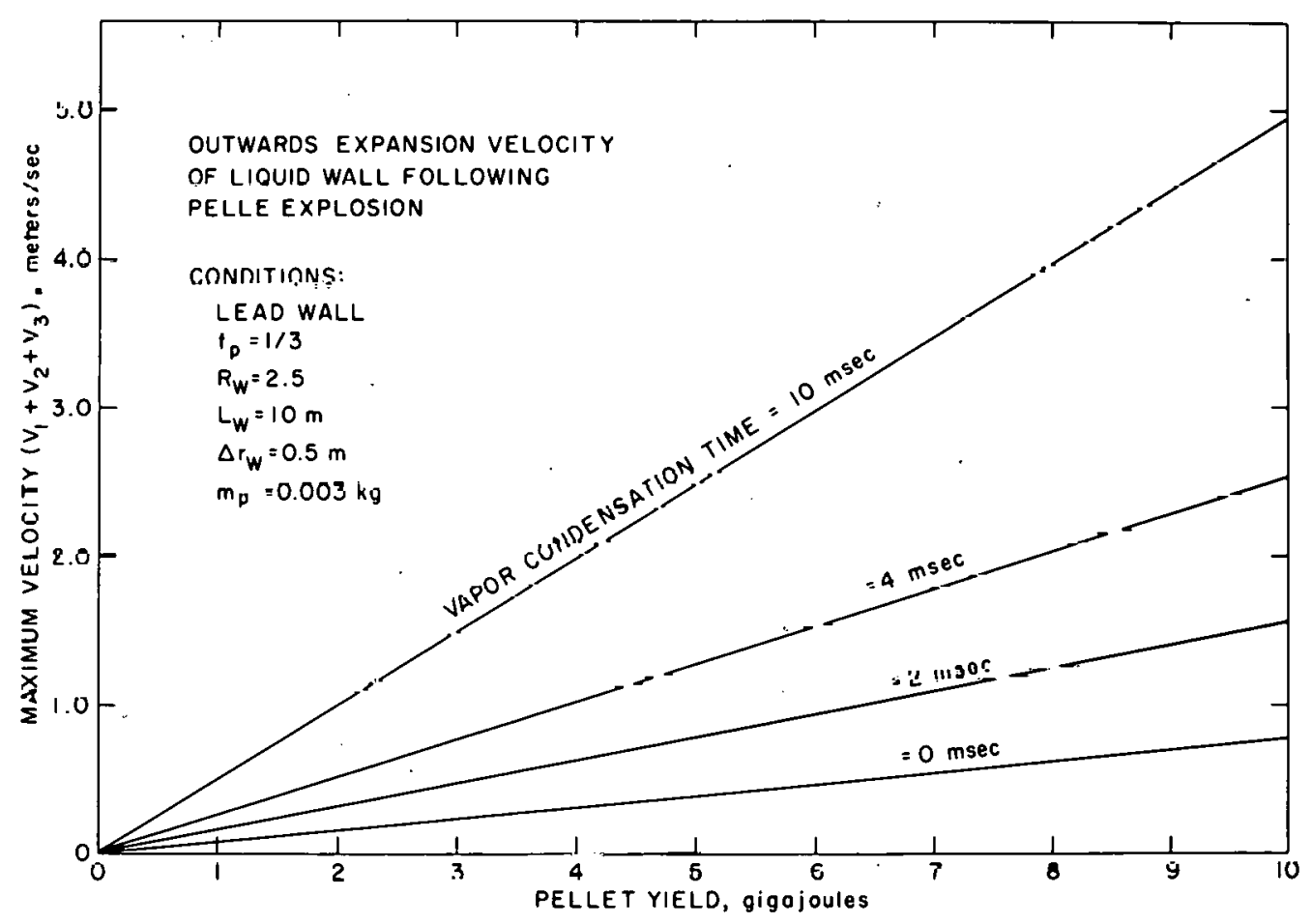

Figure 11. Expansion velocity of liquid lead wall vs. pellet yield, for different reaction chamber sizes. 


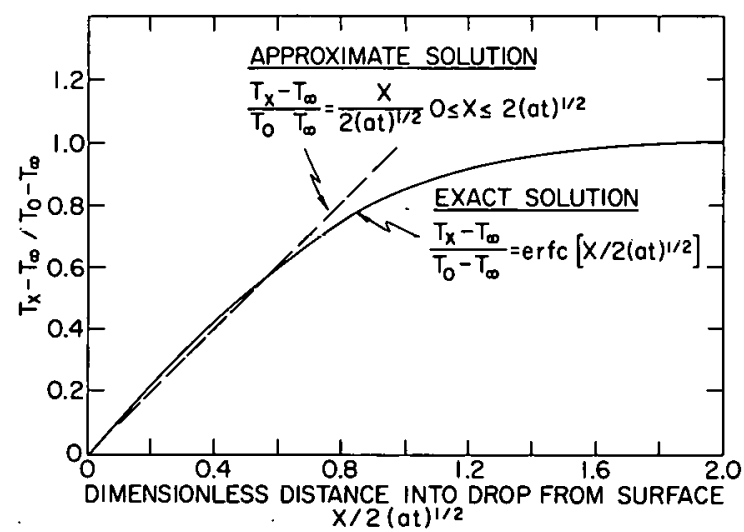

Figure 12. Temperature profile vs. time in liquid drops with condensing vapor.

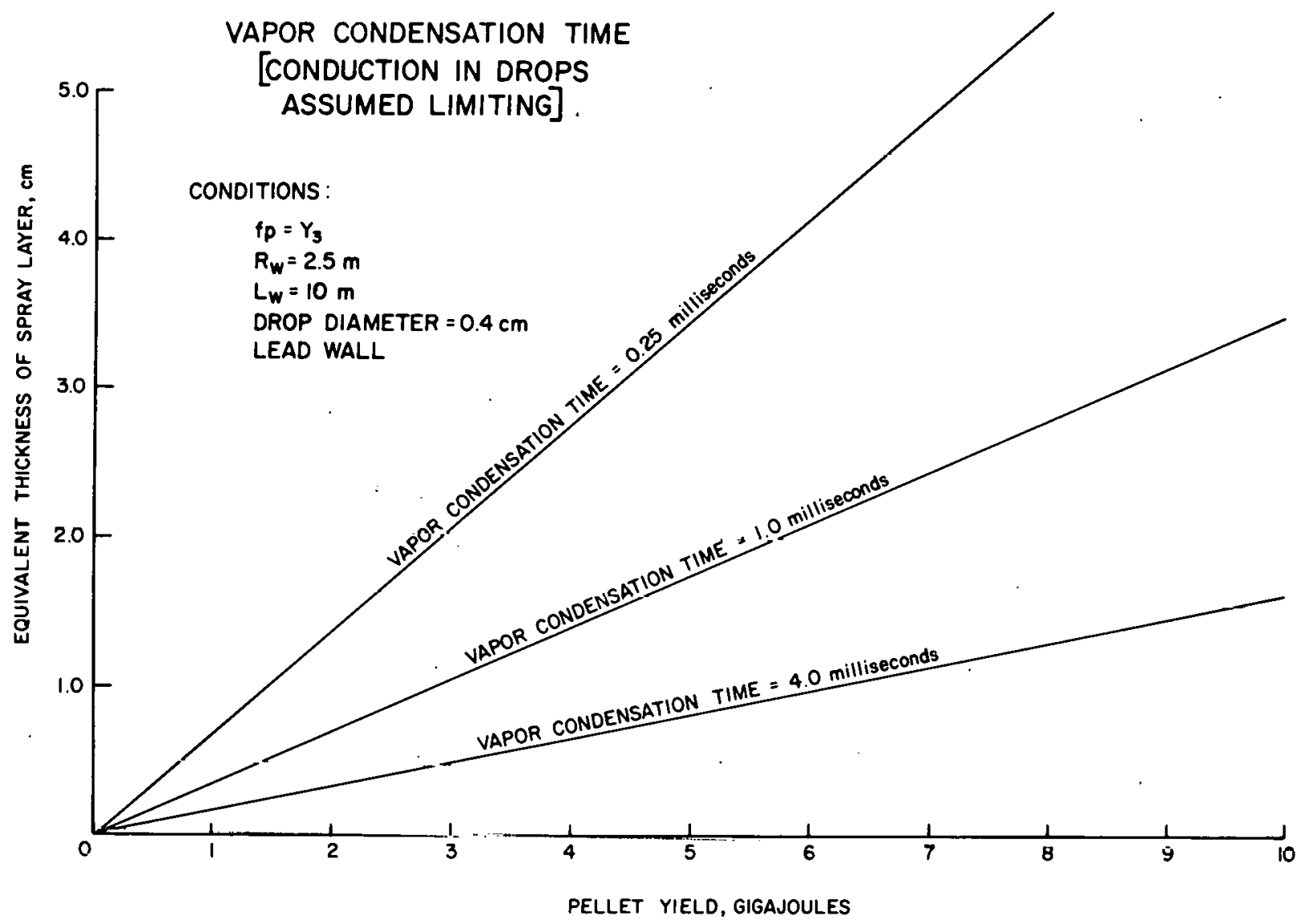

Figure 13. Vapor condensation time and thickness of liquid drop zone vs. pellet yield. 


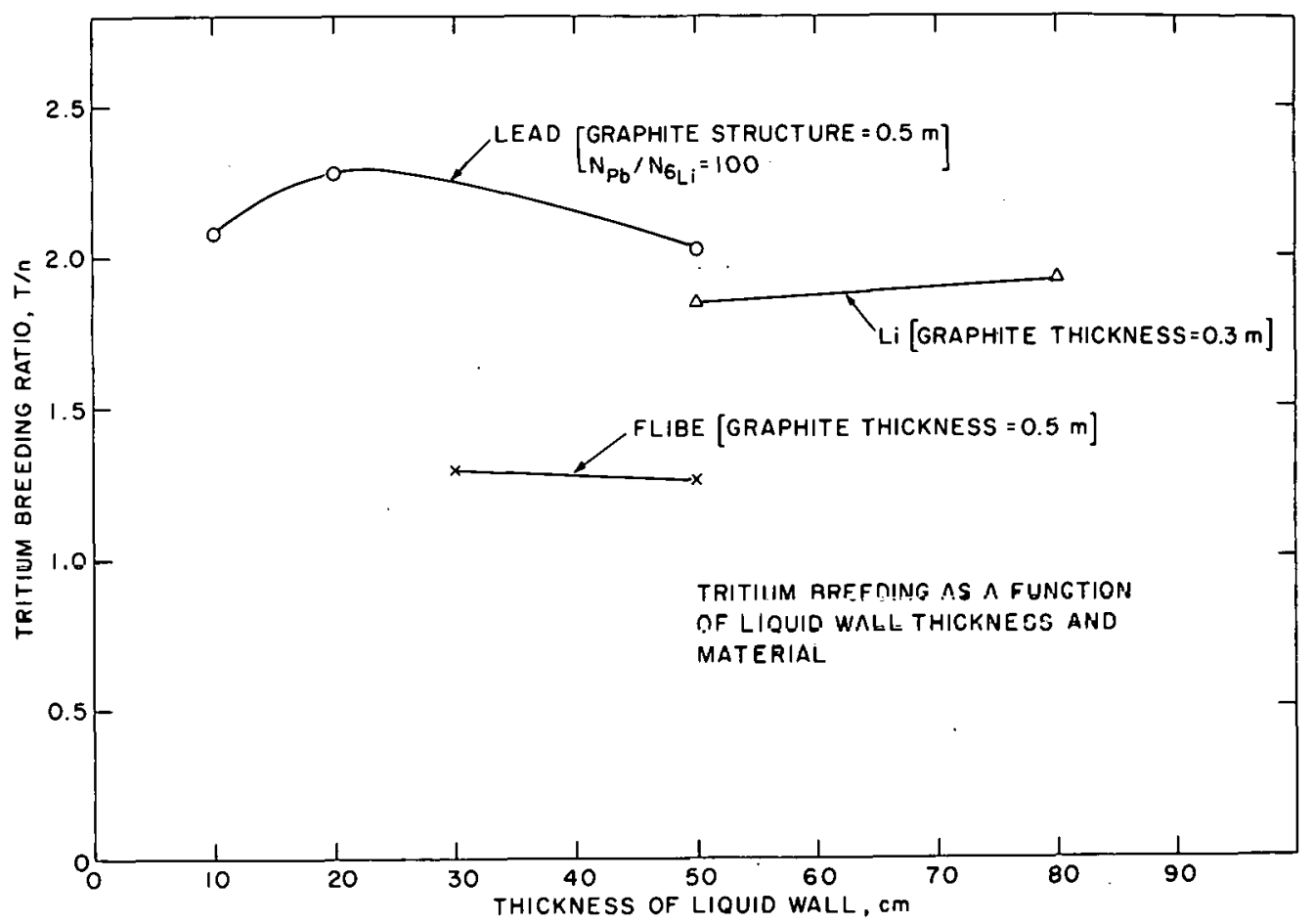

Figure 14. Tritium breeding ratio in liquid wall vs. thickness of liquid wall, for candidate liquid wall materials.

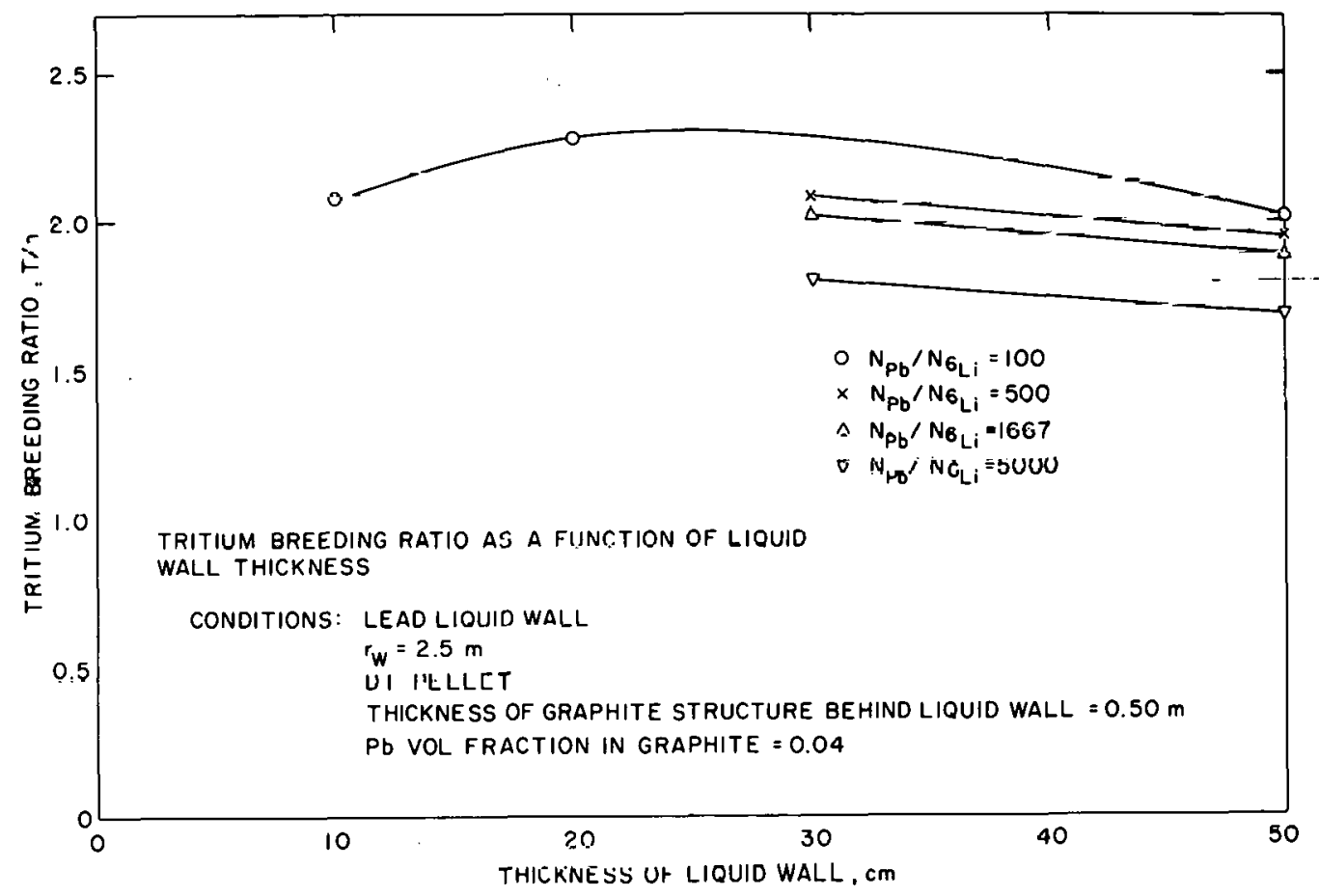

Figure 15. Tritium breeding ratio in liquid lead wall vs. thickness of lead wall, for different $\mathrm{Pb} / \mathrm{Li} 6$ ratios. 


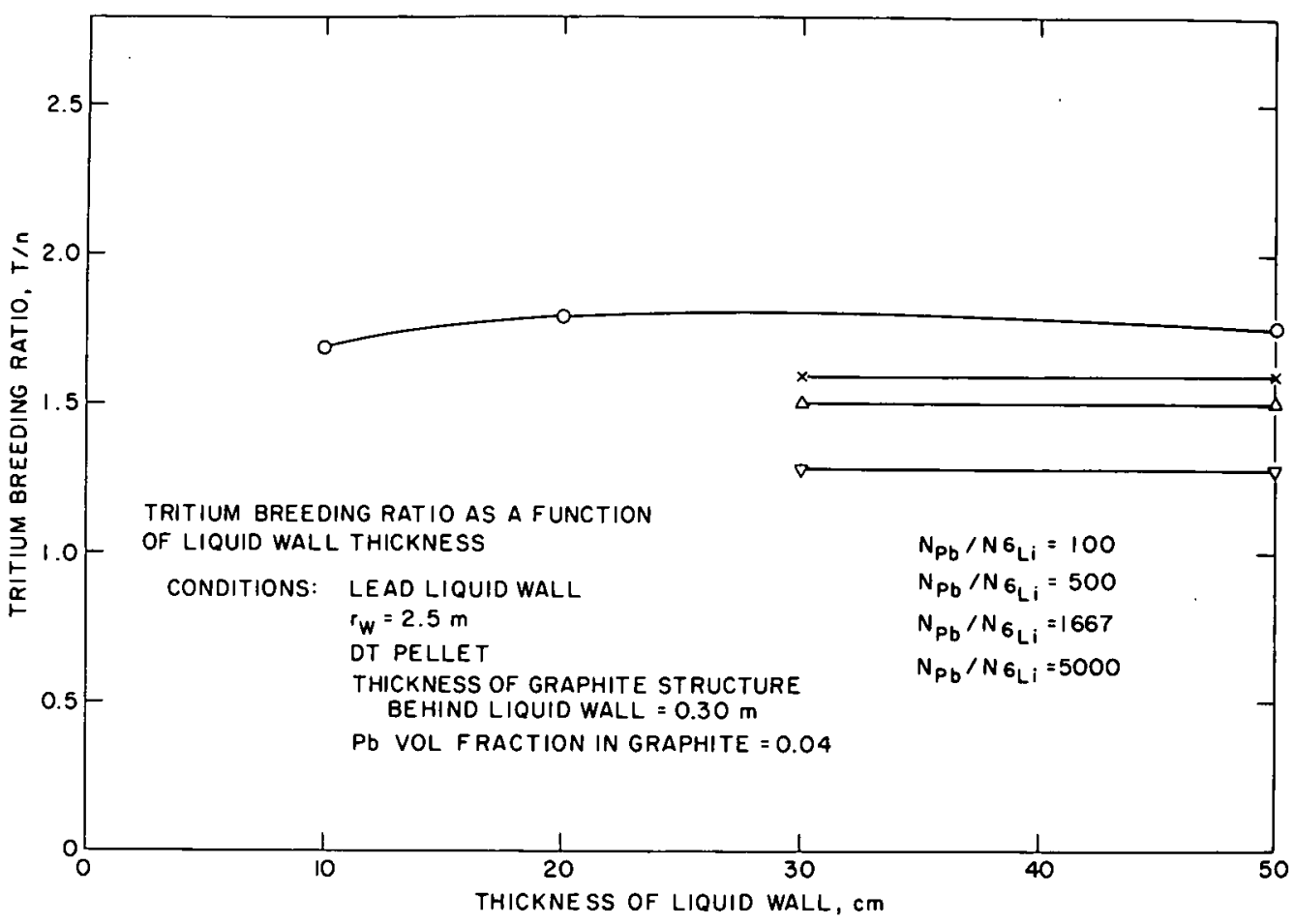

Figure 16. Tritium breeding ratio in liquid lead wall vs. thickness of lead wall, for different $\mathrm{Pb} / \mathrm{Li} 6$ ratios and thinner graphite zomes.

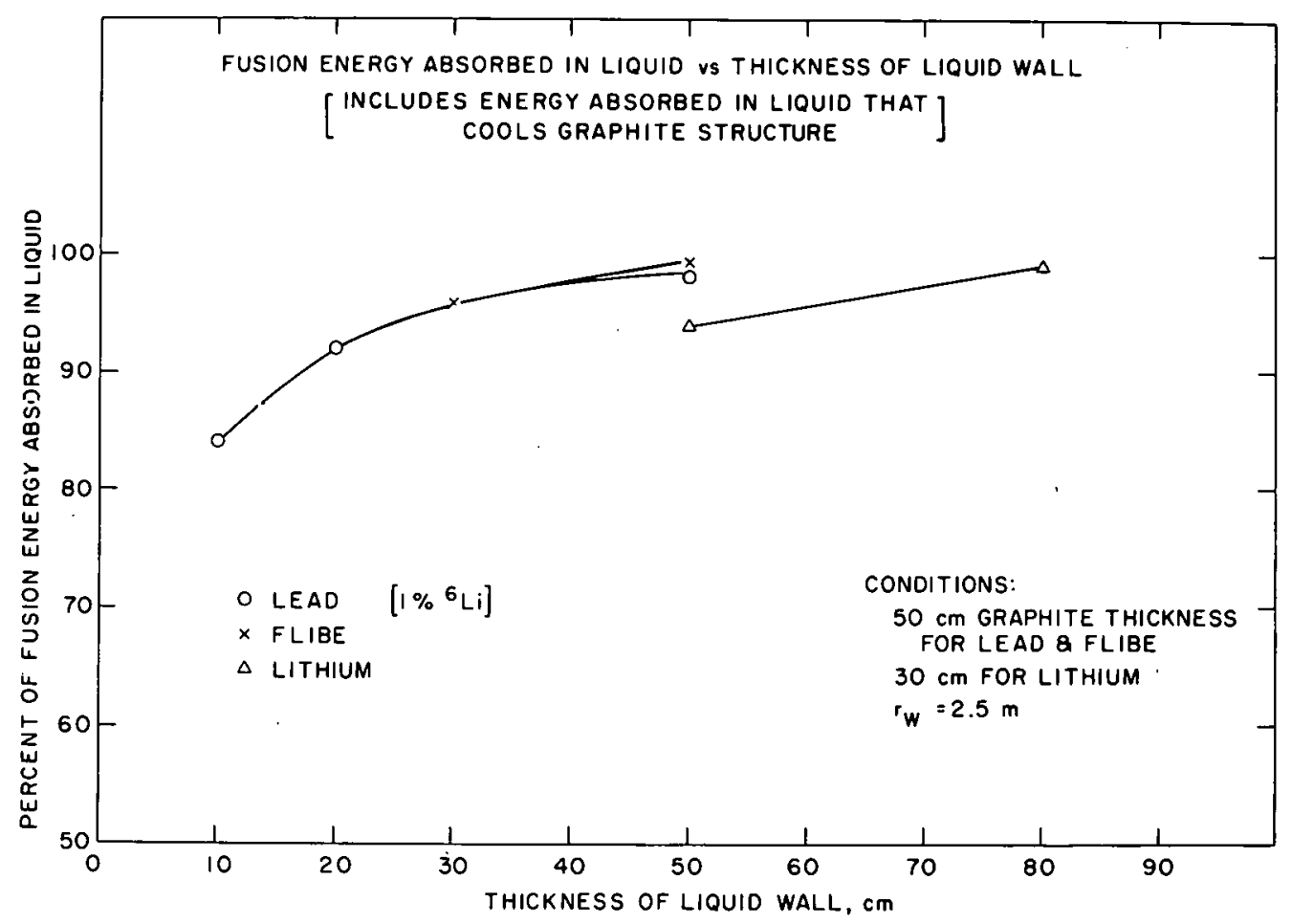

Figure 17. Direct fusion energy absorption in liquid wall and coolant vs, thickness of liquid wall, for candidate liquid wall matertals. 


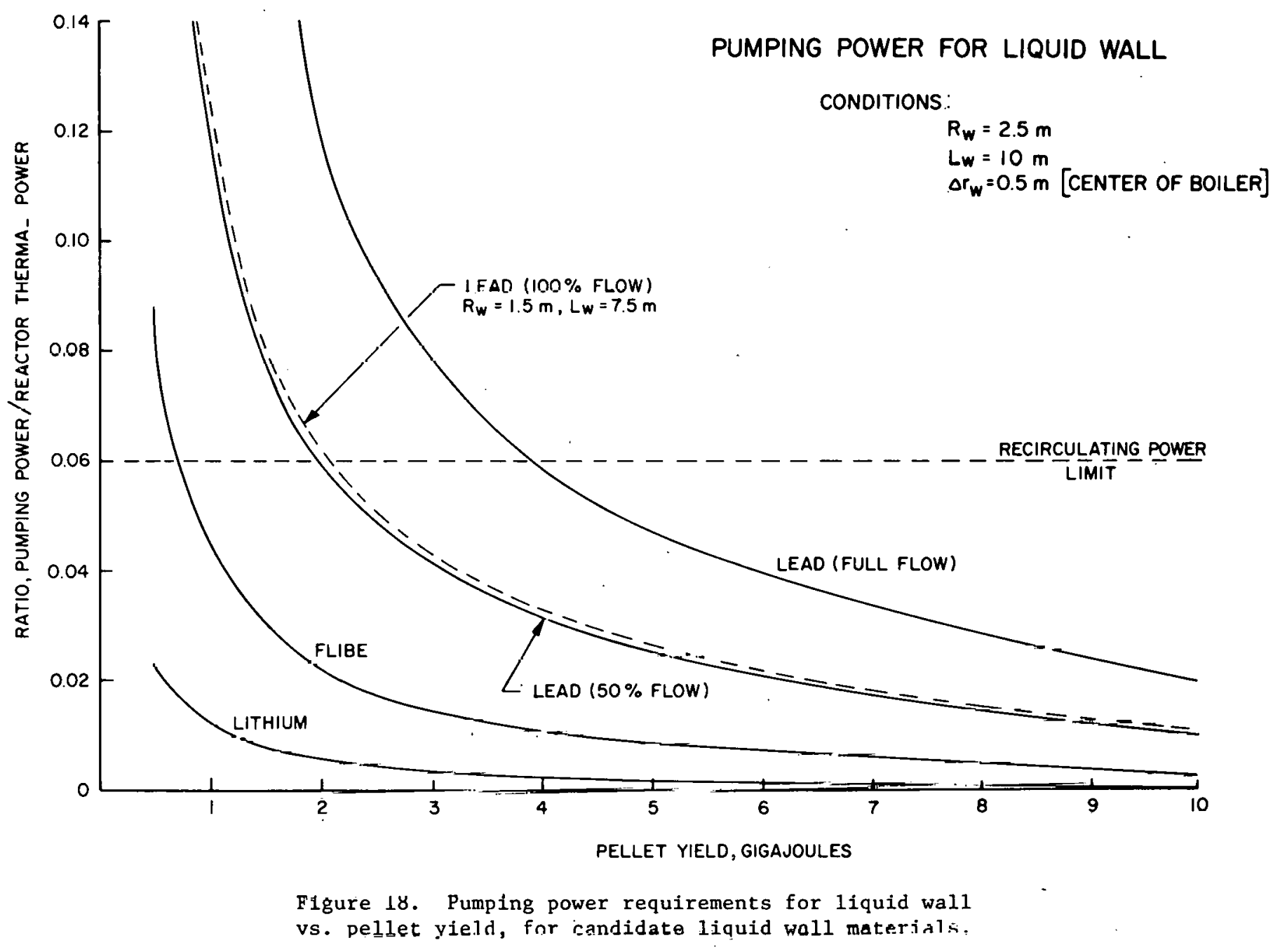

